Western University

Scholarship@Western

Civil and Environmental Engineering

Civil and Environmental Engineering

Publications

Department

6-4-2019

\title{
Equivalent standard fire duration to evaluate internal temperatures in natural fire exposed $\mathrm{RC}$ beams
}

Robert T. Kuehnen

The University of Western Ontaro, rkuehnen@uwo.ca

Maged A. Youssef

Western University, youssef@uwo.ca

Follow this and additional works at: https://ir.lib.uwo.ca/civilpub

Part of the Civil and Environmental Engineering Commons

Citation of this paper:

Kuehnen, Robert T. and Youssef, Maged A., "Equivalent standard fire duration to evaluate internal temperatures in natural fire exposed RC beams" (2019). Civil and Environmental Engineering Publications. 172.

https://ir.lib.uwo.ca/civilpub/172 
Western University

Scholarship@Western

Civil and Environmental Engineering

$9-2019$

Equivalent standard fire duration to evaluate internal temperatures in natural fire exposed RC beams

Robert Kuehnen

Maged Youssef

Follow this and additional works at: https://ir.lib.uwo.ca/civilpres

Part of the Structural Engineering Commons 


\title{
Equivalent Standard Fire Duration to Evaluate Internal Temperatures in Natural Fire Exposed RC Beams
}

\author{
R. T. Kuehnen and M. A. Youssef* \\ Western University, Department of Civil and Environmental Engineering, London, ON N6A 5B9, Canada
}

\begin{abstract}
With the recent shift towards performance-based fire design, practical methods to account for natural fire loading when designing concrete structures are needed. Available design methods and analysis approaches are based on standard fire curves. To apply these methods, a natural fire event can be converted to a standard fire with a specific duration (time equivalent). However, existing time equivalents often ignore the influence of internal temperature gradients on the section behaviour, which is unacceptable for concrete structures. To simplify analysis of RC beams exposed to fire, an average internal temperature profile (AITP) can be utilized, which records the average temperature variation along the height of a section.
\end{abstract}

This paper introduces a time equivalent method suitable for reinforced concrete (RC) beams exposed to natural fire. The method is based on the actual temperature gradient within a concrete section. Two equations are provided such that a standard duration can be determined to accurately or conservatively represent the AITP of a beam under natural fire. Characteristics of the natural fire, as well as the influence of section dimensions are accounted for. The developed time equivalent method is found to be superior to the existing for concrete sections and will provide the means for designers to estimate the severity of a natural fire event.

Keywords: Standard Fire; Natural Fire; Reinforced Concrete; Performance-Based Design; Time Equivalent

*Corresponding author. Tel.: +1 519661 2111x88661; E-mail address: youssef@uwo.ca (M.A. Youssef). 


\section{Introduction}

In the pursuit of undertaking performance-based fire design, accurately determining the severity of a fire event is an essential step. Historically, fire severity has been represented by standard temperature-time curves, as outlined in ASTM E119 (2018) and EN 1991-1-2 (2002). These curves form the basis of the existing prescriptive fire design methods. However, because standard fire curves fail to consider compartment specific parameters, they represent no relationship with natural fire events, and thus, are not suitable for performance-based design. To model natural fires, several temperature-time curve alternatives, varying greatly in complexity and implementation, have been proposed in the literature (Cooper and Steckler, 1996). As a means of industry standardization, the fire severity generated by a natural fire needs to be related back to standard fires using time equivalency. The major benefit of defining time equivalents $\left(t_{e}\right)$, is that existing data, testing, and computer programs utilizing standard fire curves, can be directly related to natural events (Buchanan, 2001). Available methods to calculate the $t_{e}$ have extensively focused on steel members, which cannot be used for reinforced concrete (RC) sections because of their unique fire-related properties and expected internal thermal gradients. This paper demonstrates the importance of internal thermal gradients in RC members, summarizes the existing time equivalent approaches, and proposes a new method to determine the $t_{e}$ for rectangular RC beams while accounting for section dimensions. 


\section{Thermal Gradient in RC Sections}

When exposed to fire, RC cross-sections develop large thermal gradients, as the temperature level slowly transfers from the surface to the inner core. Thermal gradients are well known in the literature and can be evaluated using computational methods (Lie, 1992; Franssen and Gerney, 2010) or simplified approaches (Wickström, 1986; Gao and Dai, 2014). To undertake performancebased design, the two-dimensional thermal gradients within an RC cross-section can be simplified to a one-dimensional average internal temperature profile (AITP) (El-Fitiany and Youssef, 2009). The AITP describes the temperature as a function of the section height, allowing for analysis of beams resisting uniaxial bending. Figure 1 provides a qualitative representation of the AITP for an RC beam exposed to fire on three sides. The concrete section is first divided into a two-way mesh to conduct heat transfer analysis (Figure 1a). The meshed units are subsequently grouped into horizontal layers (Figure 1b), and the average temperature for each layer is calculated. The AITP, shown in Figure 1c, represents the maximum temperature experienced by each layer throughout the fire event. Suitability of AITP in performance-based design has been proven by El-Fitiany and Youssef (2017), Alhadid (2017), Youssef et al. (2015), El-Fitiany and Youssef (2014), and El-Fitiany and Youssef (2009). Wang et al. (2013) and Guo and Shi (2011) highlighted the importance of the internal thermal gradients on evaluating RC members exposed to fire. 


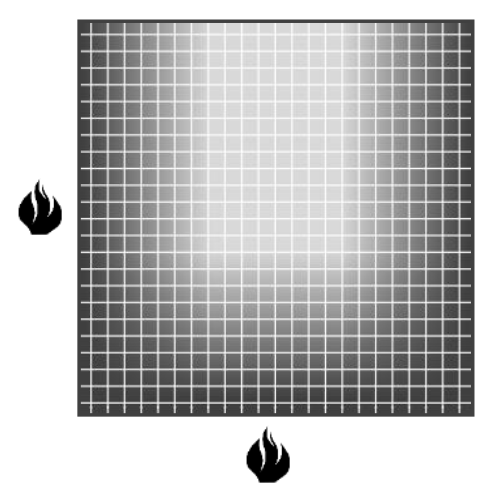

(a)

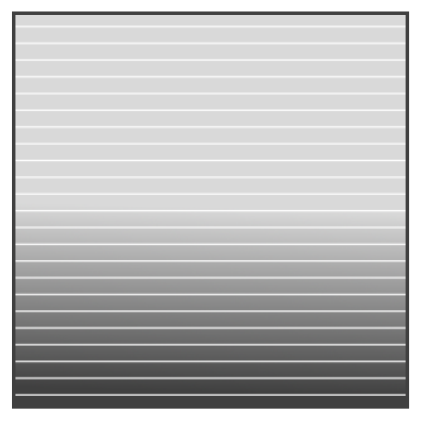

Average Temperature Layers

(b)

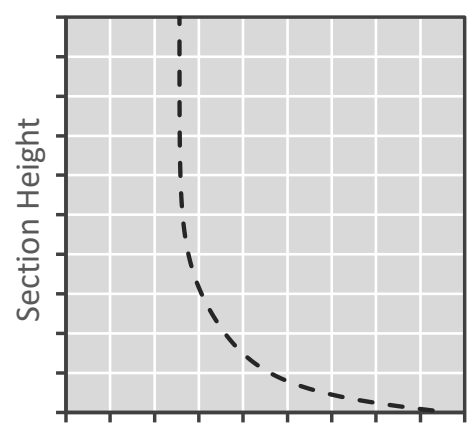

Temperature

(c)

Fig 1. Heat Transfer Modelling: (a) Heat Transfer Mesh, (b) Average Temperature Layers, and (c) AITP

\section{Existing Time Equivalent Methods}

Beginning as early as 1928, time equivalent methods representing fire severity have been presented in the literature. Eurocode broadly divides these methods into two categories: thermal and mechanical (EN 1993-1-2, 2005). Thermal methods are based on the temperature or thermal energy experienced by an element exposed to fire, while mechanical methods are based on structural behavior. A brief summary of three-thermal and two-mechanical methods is provided below.

\subsection{Equal Area Method (Thermal)}

Equal area method was the first widely recognized time equivalent theory, developed by Ingberg (1928). The $t_{e}$ is identified when the area under the standard fire curve is equal to the area under a chosen design fire curve. This method does not account for the heating rate, maximum temperature duration, or cooling rate of the design fire. Therefore, short hot fires and long cold fires, which have the same area, can be represented by the same $t_{e}$, despite having highly different heat distribution profiles (Thomas et al., 1997). 


\subsection{Maximum Temperature Method (Thermal)}

Maximum temperature method was most notably developed by Law (1971), Pettersson (1975) and Schneider et al. (1990). The $t_{e}$ is defined as the exposure duration to the standard fire required to generate the same maximum temperature within an element as produced by the design fire. The methods developed by Pettersson (1975) and Schneider et al. (1990) have subsequently been implemented in the design standards CIB (1986) and EN 1991-1-2 (2002) (Buchanan, 2001). Maximum temperature methods account for fuel load, compartment area, and ventilation; thus, providing far greater correlation to natural events than the equal area method. It is generally accepted that the Eurocode method is applicable for steel and concrete elements (Buchanan, 2001). However, Thomas et al. (1997) found the Eurocode approach to consistently produce unreliable results for concrete members. Purkiss (2007) stated that the maximum temperature approach is only valid for sections that can be characterized by a single uniform temperature, which clearly excludes concrete cross-sections given the significant internal temperature gradients within them.

\subsection{Energy Method (Thermal)}

Energy methods are explored by Harmathy and Mehaffey (1987), Harada et al. (2000), Nyman (2002), and Kodur et al. (2010). The $t_{e}$ occurs when accumulated thermal energy from the standard fire matches that from a selected design fire. Harmathy and Mehaffey (1987) estimated thermal energy based on normalized heat loads, Harada et al. (2000) considered the properties of compartment boundaries, Nyman (2002) used the thermal energy of a fire itself, and Kodur et al. (2010) focused on the cumulative energy transferred to an RC beam. Energy methods typically focus on cumulative energy, ignoring the internal thermal gradients that develop in RC sections. 
The only exception is Kodur et al.'s (2010) energy method, as it is based on a fire's ability to transfer energy specifically to an $\mathrm{RC}$ beam, it thus results in a $t_{e}$ which produces the same internal temperature gradients as the design fire.

\subsection{Load Capacity Concept (Mechanical)}

The load capacity concept focuses on the mechanical response of fire exposed elements (Xie, 2017). In this case, the $t_{e}$ is the standard fire duration at which the capacity of an element matches its lowest capacity during exposure to a selected design fire. This concept provides a high level of accuracy in representing the severity of a fire on the load capacity of a specific section, however, it requires significant experimental and/or computational effort. It also prioritizes load capacity as the basis for equivalency, leaving potentially large deviations in other mechanical responses such as deflections. A general method to calculate a $t_{e}$ based on load capacity was not found in the literature. The concept however has been used by Xie et al. (2017) to access the suitability of the maximum temperature method presented in EN 1991-1-2 (2002). Their analysis showed that the Eurocode approach often produces unconservative results for RC sections when assessing deflection as the primary response.

\subsection{Maximum Deflection Method (Mechanical)}

Maximum deflection method (MDM) uses the deflection serviceability of an element as its basis for equivalence (Buchanan, 2001). The $t_{e}$ for a specific element occurs when the deflection caused by a standard fire matches the maximum deflection caused by a selected design fire. This method entails a great deal of complexity compared to thermal methods, but it does provide highly accurate deflection predictions. Similar to the load capacity concept, deflection accuracy comes 
at the expense of other mechanical responses. Kodur et al. (2010) used this method to computationally evaluate $72 \mathrm{RC}$ beams under fire exposure, resulting in an empirical equation to determine the $t_{e}$ for RC beams.

\section{Research Significance}

The existing time equivalent methods are based on specific maximum temperature, energy, load capacity, or deflection criteria. Although these methods have been successful in the case of steel members, the large cross-sections of RC members necessitate the consideration of internal thermal gradients. Of the existing methods, none directly consider the effects of internal gradients, nor account for the influence of cross-section dimensions.

In this paper, an average internal temperature profile method is proposed as an improved measure of fire severity for RC beams. AITP method is based on the actual internal temperature gradients that develop within a concrete section, allowing for a definitive evaluation of the effect of fire on RC beams. Using this method, the $t_{e}$ is defined as the duration of standard fire required to generate the same AITP in an RC section as experienced by a selected design fire. The following sections provide details about the conducted parametric studies, the proposed AITP $t_{e}$, and a recommended size adjustment factor. 


\section{Time Equivalent Parametric Study}

\subsection{Parameters}

To examine the AITP $t_{e}$, the standard fire and design fire parameters are first defined. In North America, two standard fire curves are commonly used, as prescribed in ISO 834 (1999) and ASTM E-119 (2000). The AITP time equivalent proposed in this paper is based on the ISO standard fire; although, it should be noted that both standard fires produce nearly identical temperature-time curves (Lie, 1992).

To develop a design fire curve, Eurocode (EN 1991-1-2, 2002) provides a process that is based on a variety of compartment and fire load parameters. A number of existing time equivalent methods are linked to these parameters, allowing the methods to be easily related to the Eurocode's natural fire definition. However, doing so limits the applicability of the time equivalent to only design fires developed using the Eurocode approach. To best characterize the general form of a natural fire, the three key parameters of maximum temperature $\left(T_{\max }\right)$, time of maximum temperature $\left(t_{\max }\right)$, and overall duration ( $\left.t_{\text {final }}\right)$ need to be defined.

The valid range of the three key parameters were determined based on a preliminary study which involved the development of 1470 design fires based on the Eurocode approach. Maximum values for $t_{\text {final }}$ and $T_{\max }$ were constrained at $4-\mathrm{hr}$ and $1200^{\circ} \mathrm{C}$ to avoid unrealistically long or hot design fires. Within the acceptable ranges, a sensitivity study was undertaken to determine the optimal intervals such that the developed design fires are reasonably spaced. Values for $t_{\max }$ were chosen at 5-min intervals until $30 \mathrm{~min}$, then at 17 -min intervals until $115 \mathrm{~min}$; values for $t_{\text {final }}$ were 
chosen at 20 -min intervals throughout; and $T_{\max }$ values were chosen starting from $350^{\circ} \mathrm{C}$ at $100^{\circ} \mathrm{C}$ intervals until $650^{\circ} \mathrm{C}$, then at $50^{\circ} \mathrm{C}$ intervals until $1200^{\circ} \mathrm{C}$. Any combination with $t_{\text {max }} \geq t_{\text {final }}$ was immediately excluded, resulting in a total of 1290 design fires for evaluation. Using the three parameters, the full design fire curve can be developed by adapting the Eurocode approach (EN 1991-1-2, 2002). Equation A.1 from Eurocode defines the heating branch and a linear profile is utilized for the cooling branch.

To provide in-depth discussion about the effect of fire loading on the proposed time equivalent, six design fires were selected (Figure 2). The six fires were developed using the Eurocode approach to reflect natural fire profiles presented in Dembsey et al. (1995), Kirby et al. (1994), Lennon (2014), and Implementation of Eurocodes (2005). The design fires were broadly classified as: moderate, large, small, rapid hot, and long cool.

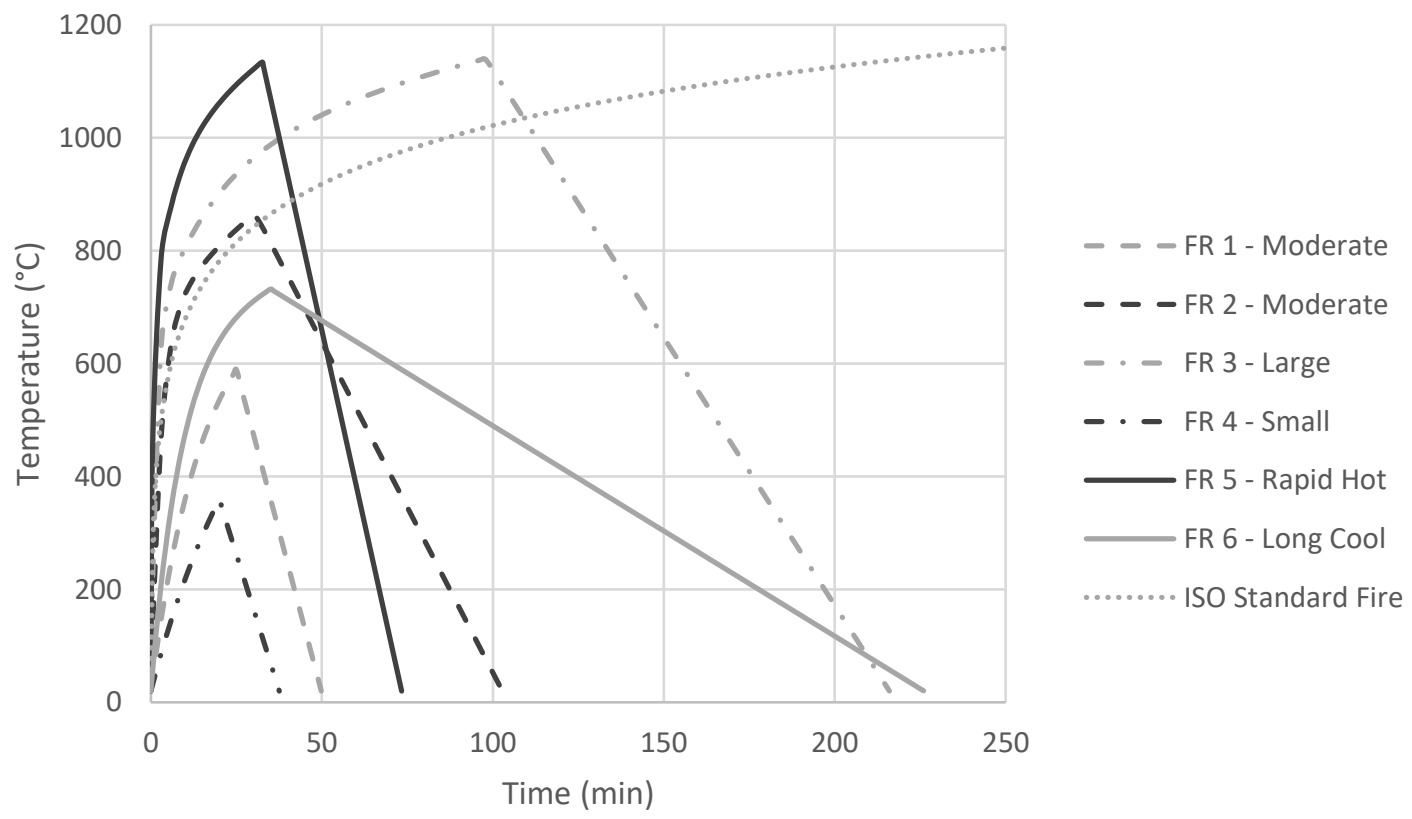

Fig 2. Representative Design Fire Profiles 
The cross-section of the theoretical concrete beam was 250 by $500 \mathrm{~mm}$. The effect of crosssection dimensions is examined in Section 6. Siliceous aggregate was assumed to standardize thermal properties.

\subsection{Methodology}

The proposed AITP $t_{e}$ is derived by developing the AITP for a selected design fire (AITP- $\left.D_{n}\right)$ and a standard fire (AITP-S $S_{t}$ ) with a trial duration $t$. Correlation between AITP- $D_{n}$ and AITP-S $S_{t}$ is judged based on either mean or conservative criteria. Mean criterion compares the percent difference between AITP-D $D_{n}$ and AITP-St at every layer of the profile and records the average percent difference for all of the layers. The duration $t$ is incrementally increased until the lowest average percent difference is found. Conservative criterion ignores error differences; the duration $t$ is incrementally increased until AITP-S $S_{t}$ has equal or larger temperatures at every layer when compared to AITP-Dn.

\subsection{AITP te Values}

Figure 3 shows the AITP mean $t_{e}$ versus the average and maximum error between the respective AITP-S and AITP-D. Of the 1290 evaluated cases, none recorded an average error in excess of $8.5 \%$, indicating a high degree of correlation. Maximum error is significantly greater for all of the considered cases, although the extent of the section affected by the high error is generally very small. Maximum deviation between AITP-S and AITP-D always arises within the lower $42.5 \mathrm{~mm}$ of the section, and often at the lower surface itself. Moving away from the point of maximum difference, the discrepancy between AITP-S and AITP-D decreases rapidly. As an example, the largest maximum error recorded was $95.3 \%$ and the corresponding average error was $8.1 \%$. This 
maximum occurred at the element's surface (distance $=0 \mathrm{~mm}$ ). At a distance of just $37.5 \mathrm{~mm}$ into the section, the error reduced to $15 \%$, and by $57.5 \mathrm{~mm}$ the error fell below $10 \%$. As such, even though the maximum error is large in value, its influence on the concrete section as a whole is relatively minor. Cases with the largest error are typically attributed to small fires, with low temperature over a short duration. Due to the intended purpose of the standard fire as a representation of a worst-case fire event, small fires are difficult to represent, resulting in the observed high deviation between AITP-S and AITP-D.

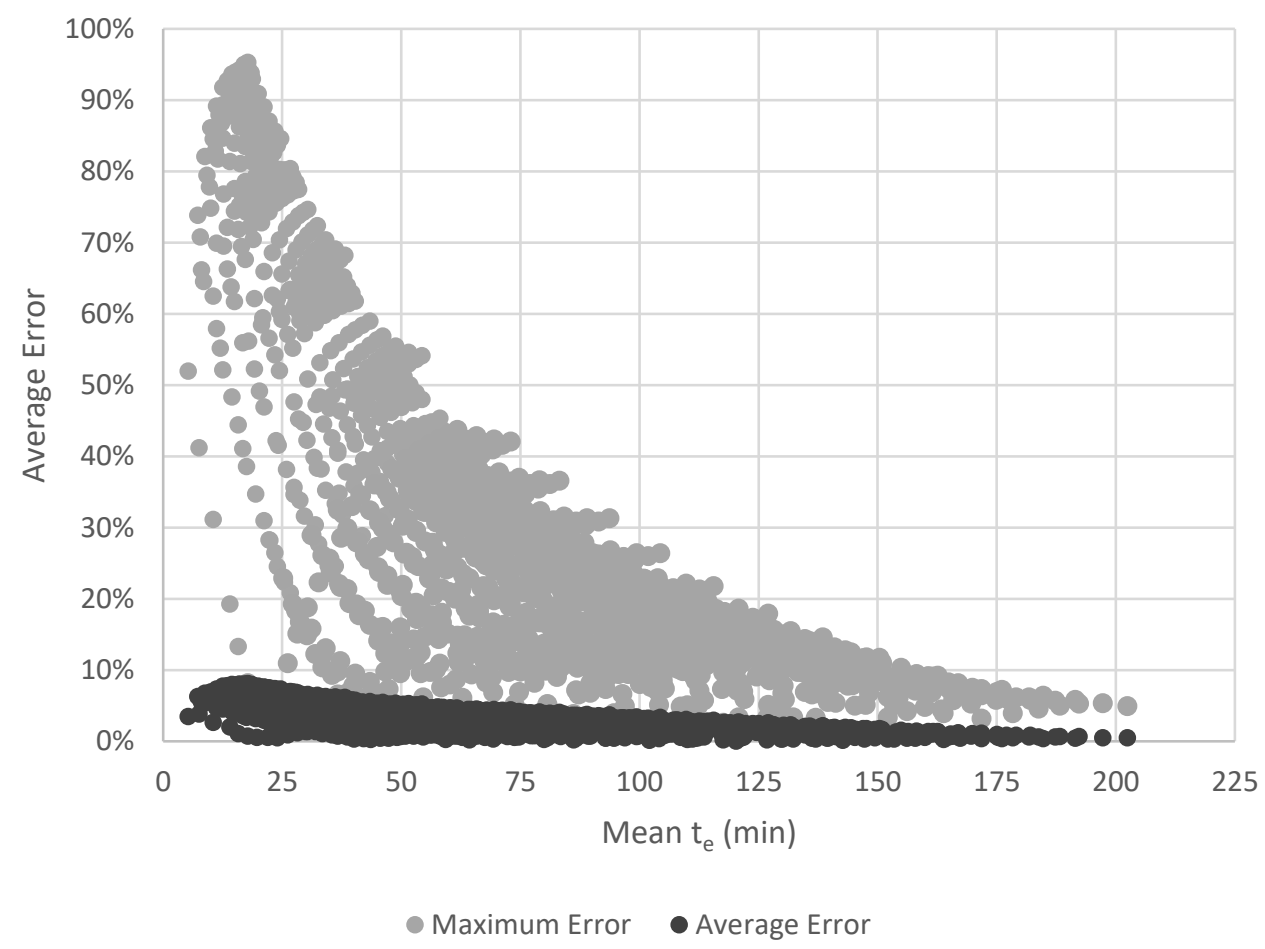

Fig 3. Accuracy of AITP Mean Time Equivalent for Average and Maximum Error

Calculation method for the mean and conservative $t_{e}$ is proposed by the general Equation 1, with coefficients $A$ through J given in Table 1 . The equation and coefficients were determined using a least-squared regression analysis, common regression requirements of probability $(p)<0.001$ and 
correlation $\left(R^{2}{ }_{a d j}\right)>95 \%$ were maintained. In Equation 1, $T_{\max }$ is the maximum fire temperature $\left({ }^{\circ} \mathrm{C}\right), t_{\max }$ is the corresponding time $(\min )$, and $t_{\text {final }}$ is the overall duration of the fire (min). Following Eurocode guidelines, the time variables $t_{\max }$ and $t_{\text {final }}$ are measured from the point of flashover, and $t_{\text {final }}$ is measured to the end of the decay phase, ignoring the relatively negligible impact of a fire's ignition and extinction periods.

$$
\begin{aligned}
t_{e}= & A+B t_{\text {max }}+C t_{\text {final }}+D T_{\text {max }}+E t_{\text {max }}^{2}+F t_{\text {final }}^{2}+G T_{\text {max }}^{2}+H t_{\text {max }} t_{\text {final }} \\
& +I t_{\max } T_{\max }+J t_{\text {final }} T_{\max }
\end{aligned}
$$

\begin{tabular}{|c|c|c|c|c|c|c|}
\hline \multirow{4}{*}{ 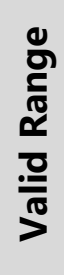 } & \multirow{4}{*}{$\begin{array}{c}t_{\max }(\min ) \\
t_{\text {final }}(\min ) \\
T_{\max }\left({ }^{\circ} \mathrm{C}\right)\end{array}$} & \multirow{4}{*}{$\begin{array}{l}\text { Mean Criterion } \\
\begin{array}{r}15-115 \\
20-240 \\
350-1100\end{array}\end{array}$} & \multicolumn{4}{|c|}{ Conservative Criterion } \\
\hline & & & \multicolumn{4}{|c|}{$15-115$} \\
\hline & & & \multicolumn{4}{|c|}{$20-240$} \\
\hline & & & $350-750$ & $750-950$ & $950-1100$ & $1100-1200$ \\
\hline \multirow{10}{*}{ 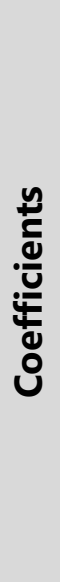 } & A & 8.124 & 8.685 & 2.370 & 566.30 & 4404.0 \\
\hline & B & -0.153 & -0.0829 & -0.0893 & -0.465 & -5.745 \\
\hline & C & 0.0384 & 0.0324 & 0.0446 & 1.188 & 1.039 \\
\hline & D & -0.0431 & -0.0428 & -0.0186 & -1.332 & -8.177 \\
\hline & $\mathbf{E}$ & $-8.53 \times 10^{-4}$ & $-4.74 \times 10^{-4}$ & $-9.42 \times 10^{-4}$ & $-20.00 \times 10^{-4}$ & $-80.87 \times 10^{-4}$ \\
\hline & $\mathbf{F}$ & $-6.46 \times 10^{-4}$ & $-4.16 \times 10^{-4}$ & $-7.39 \times 10^{-4}$ & 0.0 & $2.99 \times 10^{-4}$ \\
\hline & G & $0.50 \times 10^{-4}$ & $0.66 \times 10^{-4}$ & $0.35 \times 10^{-4}$ & $7.95 \times 10^{-4}$ & $38.36 \times 10^{-4}$ \\
\hline & H & $3.44 \times 10^{-4}$ & $1.57 \times 10^{-4}$ & $4.77 \times 10^{-4}$ & $-3.07 \times 10^{-4}$ & $-17.80 \times 10^{-4}$ \\
\hline & $\mathbf{I}$ & $6.55 \times 10^{-4}$ & $5.33 \times 10^{-4}$ & $5.40 \times 10^{-4}$ & $12.05 \times 10^{-4}$ & $69.36 \times 10^{-4}$ \\
\hline & J & $4.52 \times 10^{-4}$ & $3.70 \times 10^{-4}$ & $4.71 \times 10^{-4}$ & $-9.00 \times 10^{-4}$ & $-8.40 \times 10^{-4}$ \\
\hline
\end{tabular}

Table 1. Coefficients for Equation 1

The valid ranges of the fire parameters are given in the table based on the extents of the parametric study. Fires outside of these valid ranges may be represented by the equations, but were not validated in this study. Due to the greater variability of the conservative $t_{e}$, four sets of 
coefficients are given, each is valid for the shown $T_{\max }$ range. These four ranges were determined by undertaking a sensitivity study to group design fires of similar severity. Figure 4 plots the $t_{e}$ calculated analytically versus that evaluated using the mean and conservative equations to demonstrate their suitability.

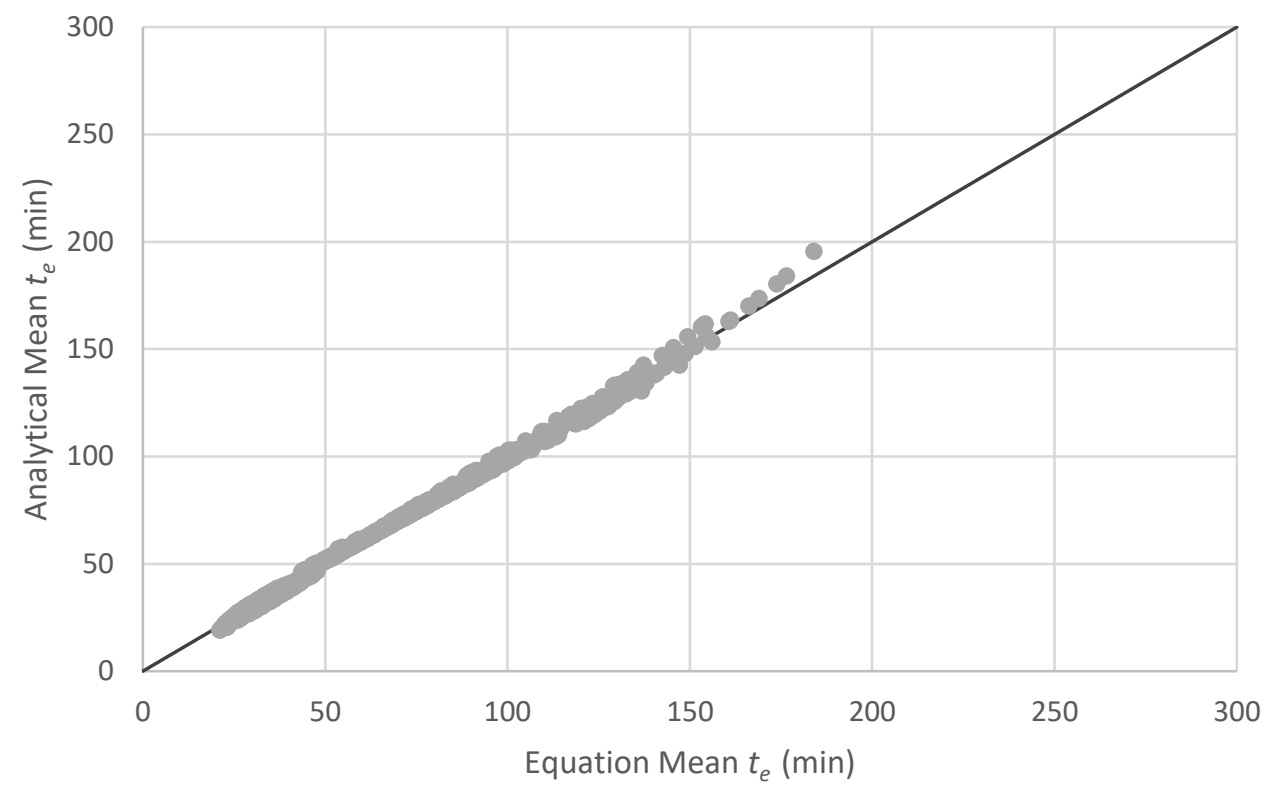

(a)

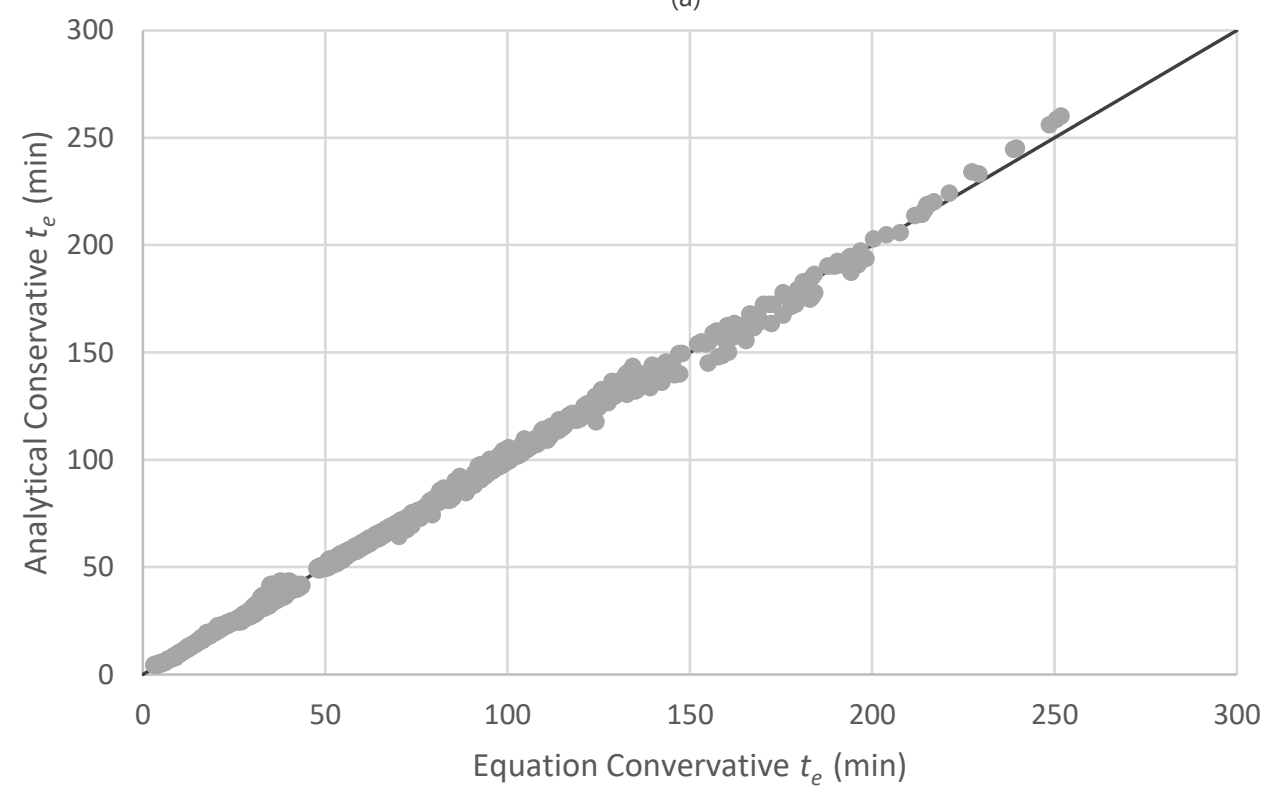

Fig 4. Accuracy of Time Equivalent Equations: (a) Mean Criterion and (b) Conservative Criterion 


\section{Size Adjustment Factor}

\subsection{Influence of Beam Width and Height}

In this section, the effect of beam width $\left(b_{c}\right)$ and height $\left(h_{c}\right)$ on the AITP $t_{e}$ is investigated. To the best of the author's knowledge, none of the existing time equivalent methods have considered section dimensions, despite its importance on defining the internal temperature gradients. Figure 5 displays the AITP of eight beams with $b_{c}$ of $250,400,600$, and $800 \mathrm{~mm}$; and $h_{c}$ of 500 and 800 $\mathrm{mm}$. The sections were exposed on three sides to a 1-hr standard fire. Width variation significantly influences the AITP. Increasing the width from 250 to $800 \mathrm{~mm}$ reduces the temperature values by $94 \%$ for this sample fire. In contrast, height can be seen to have little to no impact on the AITP. The thermal prolife recording the largest temperature values, corresponds to the beam with the smallest width. Wider elements, which have a larger interior to surface area ratio, experience a lower average internal temperature.

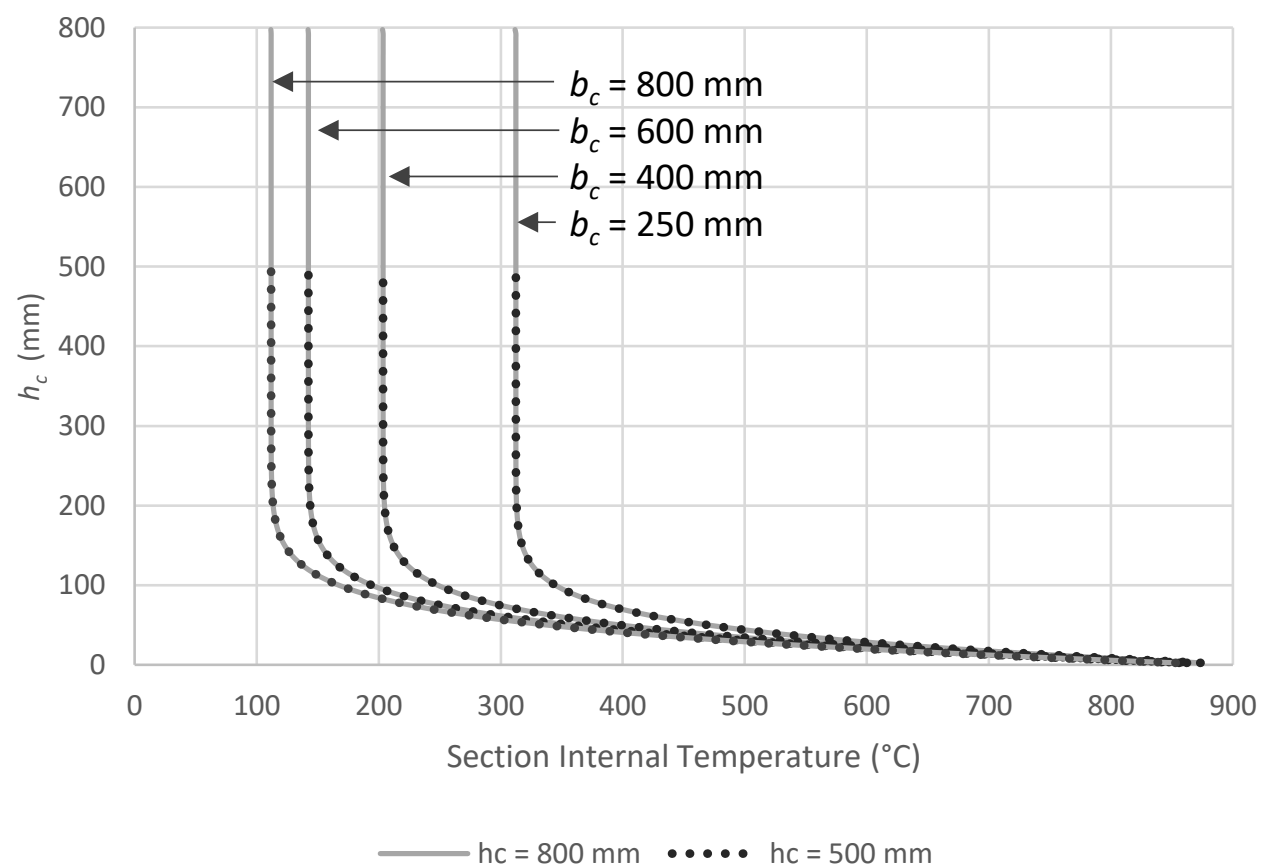

Fig 5. Average Internal Temperature Profile due to 1-hr Standard Fire for Variable Cross-Sections 
Figure 6 demonstrates the impact of $b_{c}$ on the AITP mean and conservative $t_{e}$ for five beams with $b_{c}$ of $250,400,600$, and $800 \mathrm{~mm}$ and an $h_{c}$ of $500 \mathrm{~mm}$. The sections are exposed to the six design fires defined in Section 5.1. The results indicate that as width increases, an equal or greater $t_{e}$ is required for the larger and longer duration fires. Therefore, despite the average temperature becoming cooler with increasing width, it is inaccurate and unconservative to represent a wider beam with the $t_{e}$ derived for a smaller cross-section. The necessary increase in duration of the standard fire is highly dependent on the design fire. For instance, the smaller and shorter fires (FR 1, FR 4, and FR 5), are only capable of significantly heating the exterior layers of a beam, and only require minimal alteration to the $t_{e}$ when width increases. Inversely, the larger and longer fires (FR 2, FR 3, and FR 6), require significant increases to the standard fire duration as these longer fires are able to slowly heat the entirety of a section.

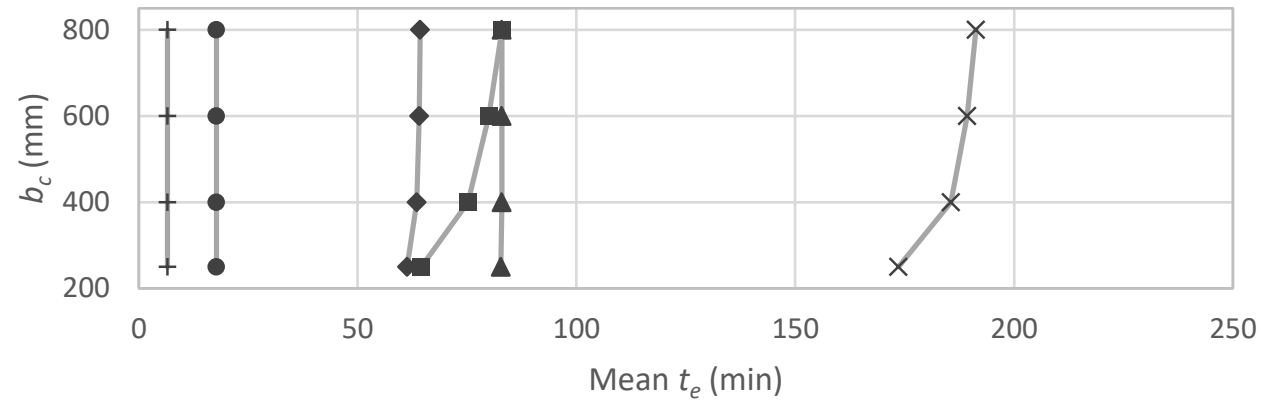

(a)

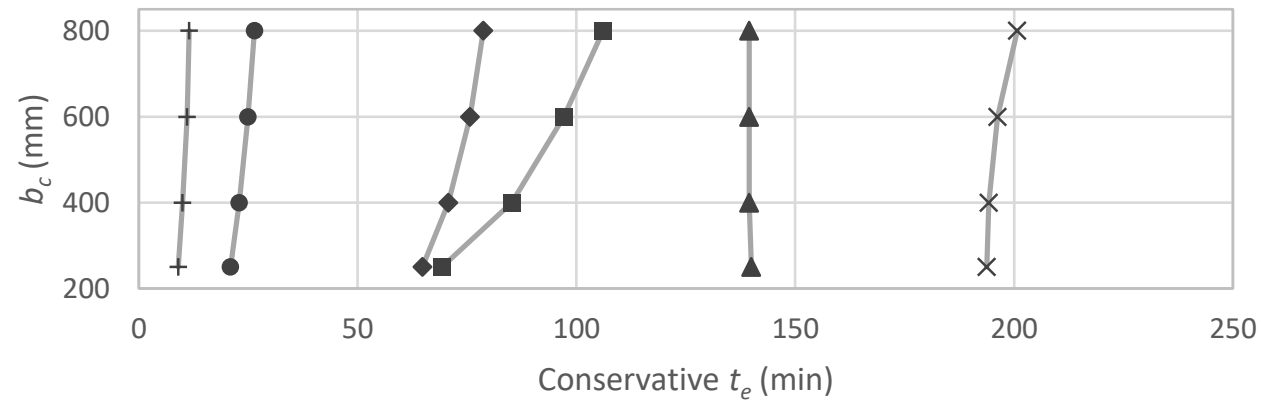

(b)

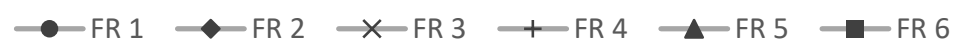

Fig 6. Sensitivity of te to Section Width (a) Mean Criterion and (b) Conservative Criterion 


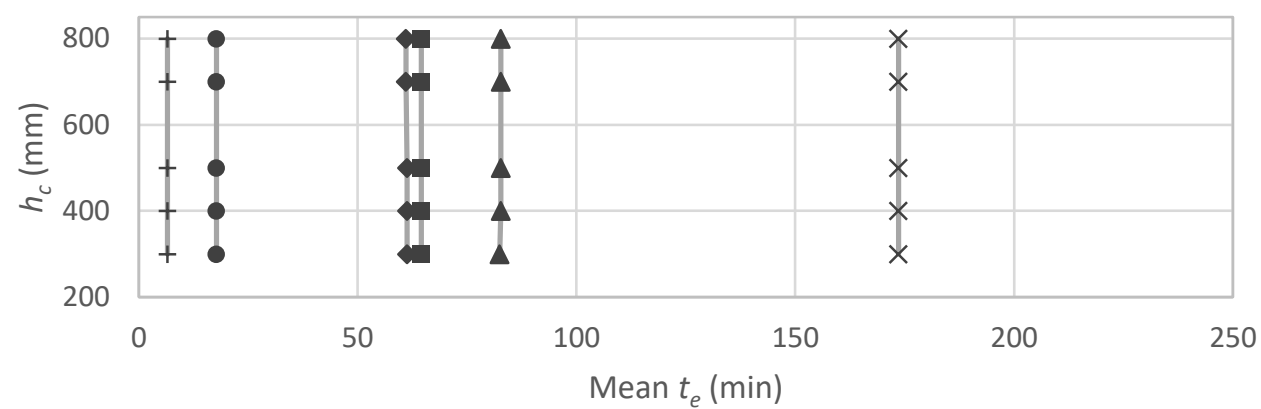

(a)

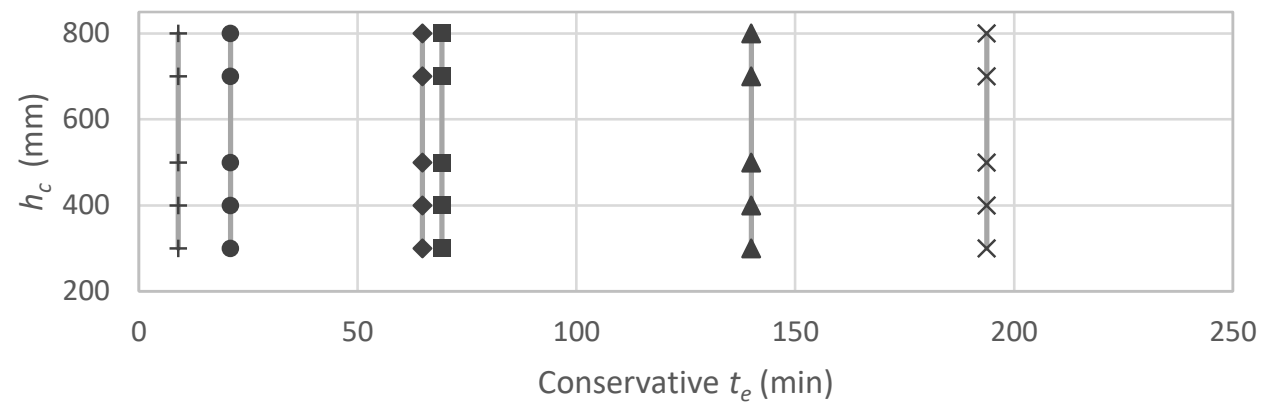

(b)

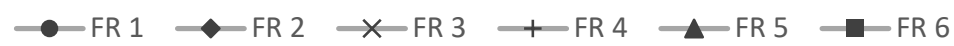

Fig 7. Sensitivity of $t_{e}$ to Section Height (a) Mean Criterion and (b) Conservative Criterion

Figure 7 provides a similar comparison of the effect of variable heights on the AITP $t_{e}$. Sections were evaluated with $h_{c}$ at $300,400,500,700$, and $800 \mathrm{~mm}$, and $b_{c}$ held constant at $250 \mathrm{~mm}$. As previously determined, the height of RC beams has no impact on the mean or conservative $t_{e}$. Despite this, when the section height is compared against the average error between AITP-D and AITP-S (Figure 8), a notable influence can be observed. As height increases, the correlation between the two profiles improves markedly. This trend can be explained by examining the AITP profile. AITP's have two major zones, a zone of constant temperature and a zone of transient temperature, as shown on Figure 9. For taller beams, the constant zone dominates the average error calculation, while for shorter beams, the transient zone plays a more significant role. As the error values are low in the constant zone, the average error will seem to be affected by the section height. Thus, shorter beams will give higher error than taller beams, regardless of the fact that 
both have almost matching AITPs. This effect does not influence the conservative $t_{e}$. To remove the zoning effect, error values are normalized using Equation 2, allowing for near constant error regardless of section height or design fire. The 0.45 factor in Equation 3 was selected such that the normalized average error will be equal to the actual average error, for the moderate fire FR 2 when section height is $500 \mathrm{~mm}$.

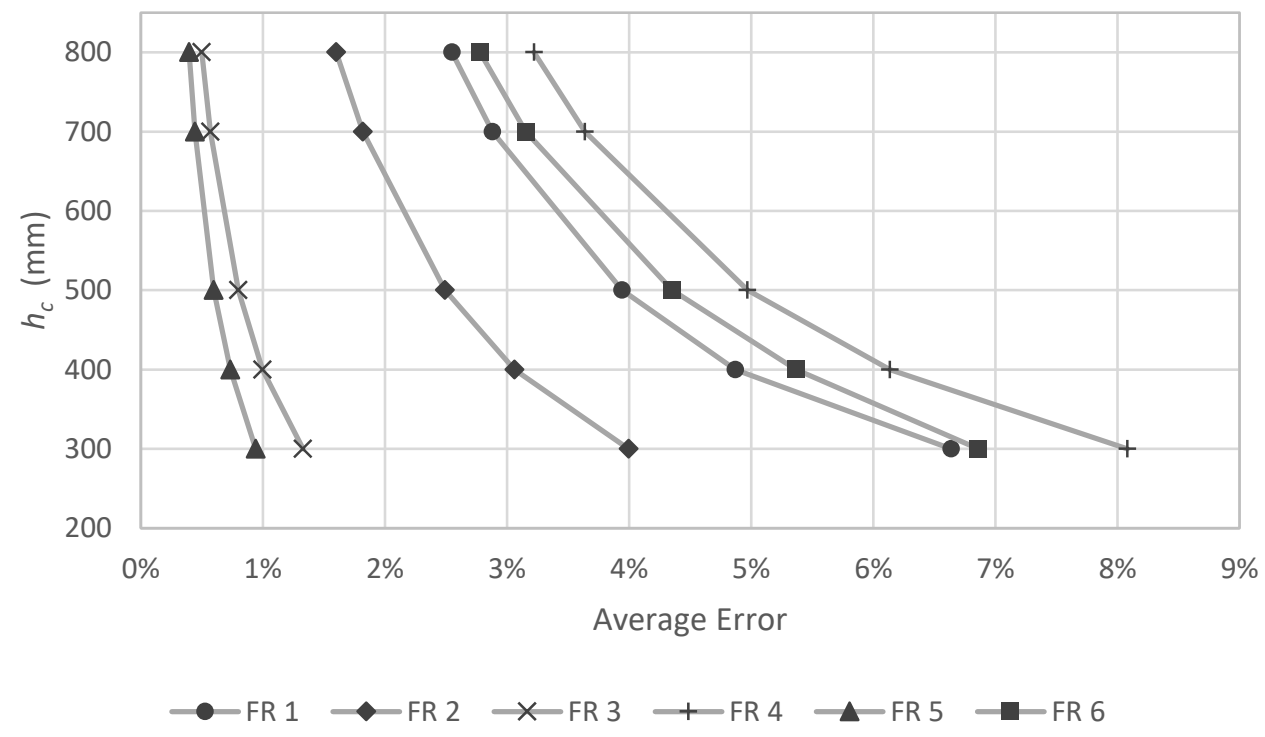

Fig 8. Section Height versus Average Error for Mean Criterion

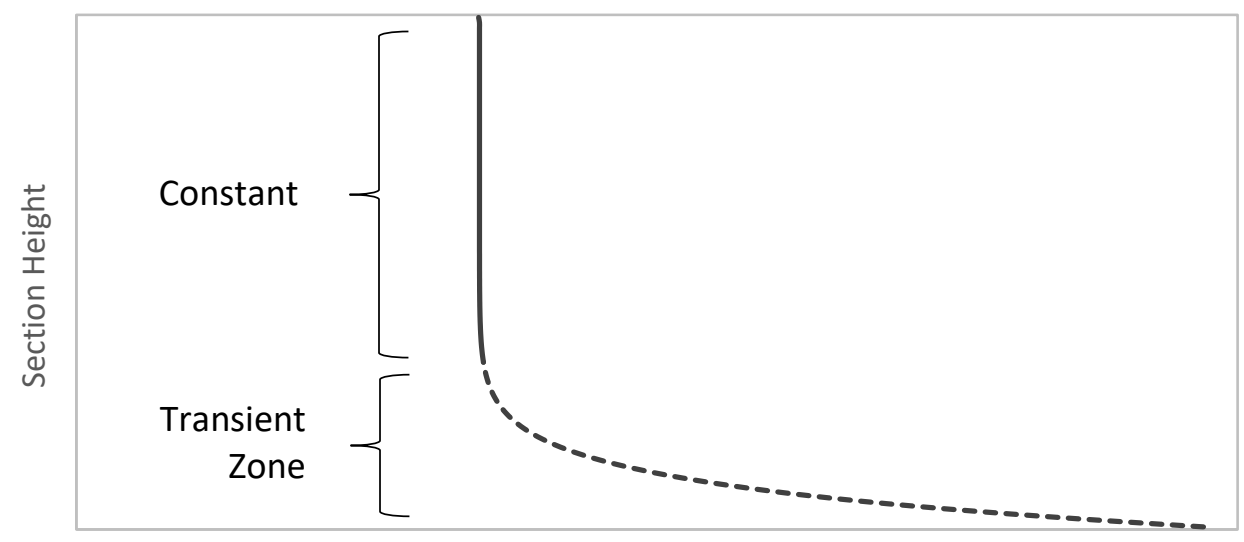

Section Internal Temperature

Fig 9. AITP Zones 


$$
\text { Normalized Error }=\text { Error } * \frac{\text { Transient Zone Height }}{0.45 \text { Section Height }}
$$

To develop a general equation to account for beam dimensions, a parametric study was undertaken on sections with $b_{c}$ of $250,400,600$, and $800 \mathrm{~mm}$. Height was held constant throughout the study at $500 \mathrm{~mm}$, with normalized results used to evaluate the mean criterion. The methodology presented in Section 5.2 was followed. Standard and design fires were assembled consistent with the process outlined in Section 5.1 and applied to all 4 cross-sections, resulting in 5160 cases for evaluation.

\subsection{AlTP Size Adjustment Factor}

To account for beam cross-section, a size adjustment factor $\left(\psi_{\text {size }}\right)$ is provided to be multiplied by the $t_{e}$ given in Equation 1. The $\psi_{\text {size }}$ is presented in Equation 3; wherein $b_{c}$ is the section width $(\mathrm{m})$, $T_{\max }$ is the maximum fire temperature $\left({ }^{\circ} \mathrm{C}\right), t_{\max }$ is the corresponding time $(\min )$, and $t_{\text {final }}$ is the overall duration of the fire $(\mathrm{min})$. The coefficients for Equation 3 can be found in Table 2. Both the mean and conservative criteria were developed using regression analysis. Valid ranges are prescribed based on the range of design fires for which the equations have been derived and validated. 


$$
\psi_{\text {size }}=\left\{\begin{array}{l}
1.0 \text { for }\left\{\begin{array}{l}
b_{c}<350 \\
\text { conservative } t_{e} \text { and } T_{\max }>1150^{\circ} \mathrm{C} \\
\text { conservative } t_{e} \text { and } t_{e}>180 \mathrm{~min}
\end{array}\right. \\
A+B t_{\text {max }}+C t_{\text {final }}+D T_{\text {max }}+b_{c}\left(E+F t_{\text {max }}+G t_{\text {final }}+H T_{\text {max }}\right) \geq 1.0
\end{array}\right.
$$

Table 2 Coefficients for Equation 3

\begin{tabular}{c|c|c}
\hline & Mean Criterion & Conservative Criterion \\
\hline & $15 \leq t_{\max } \leq 115 \mathrm{~min}$ & $15 \leq t_{\max } \leq 115 \mathrm{~min}$ \\
Valid Range & $20 \leq t_{\text {final }} \leq 240 \mathrm{~min}$ & $20 \leq t_{\text {final }} \leq 240 \mathrm{~min}$ \\
& $600 \leq T_{\max } \leq 1200^{\circ} \mathrm{C}$ & $350 \leq T_{\max } \leq 1200^{\circ} \mathrm{C}$ \\
\hline A & $T_{\max }<750^{\circ} \mathrm{C} \& t_{\max } \geq 60 \mathrm{~min}$ & \\
B & 1.022 & 0.819 \\
C & $-2.57 \times 10^{-4}$ & $3.78 \times 10^{-4}$ \\
D & $2.69 \times 10^{-4}$ & $-2.23 \times 10^{-4}$ \\
E & $-0.22 \times 10^{-4}$ & $1.82 \times 10^{-4}$ \\
F & 0.113 & 1.037 \\
G & $-8.23 \times 10^{-4}$ & $-27.00 \times 10^{-4}$ \\
H & $14.01 \times 10^{-4}$ & $27.15 \times 10^{-4}$ \\
\hline
\end{tabular}

The value of the $\psi_{\text {size }}$ is set equal to 1.0 for specific cases to improve the accuracy of the equation in matching the analytical data. The rational for these cases is given in this paragraph. The $\psi_{\text {size }}$ should not be taken less than one, due to the $t_{e}$ increasing with $b_{c}$. For small beams with $b_{c}<350$ $\mathrm{mm}$, the base equation without adjustment can be used, and thus the $\psi_{\text {size }}$ equals 1.0. A trend unique to the conservative $t_{e}$ necessitates the additional two constraints. When beams are narrow, heating from both sides causes the internal temperatures to rise significantly. In these cases, the critical point of the conservative $t_{e}$, where AITP-S is equal to AITP-D, is often at a height well away from the beams lower surface. As $b_{c}$ increases, the effects of two-sided heating are diminished, 
reducing the internal temperatures, and causing the critical point to shift towards the lower surface. Once the critical point is at the surface, $b_{c}$ has negligible influence on the surface temperature, and thus, negligible influence on the $t_{e}$. In this case, the $\psi_{\text {size }}$ remains at a value of 1.0 even as $b_{c}$ increases; because this is opposite of the larger trend, which finds that $t_{e}$ increases with $b_{c}$, it is difficult to capture with the equation. To alleviate the issue, condition terms ( $T_{\max }>$ $1150^{\circ} \mathrm{C}$ and/or $t_{e}>180^{\circ} \mathrm{C}$ ) were manually derived by an iterative process, for which the $\psi_{\text {size }}$ is equal to 1.0 .

Final results of the study are presented in Figure 10, plotting the analytical versus equation-based $t_{e}$ for results with and without the $\psi_{\text {size. }}$ It can be seen that for both mean and conservative criteria, the $t_{e}$ with $\psi_{\text {size }}$ exhibits far superior fit and significantly less deviation, especially on the unconservative side. 


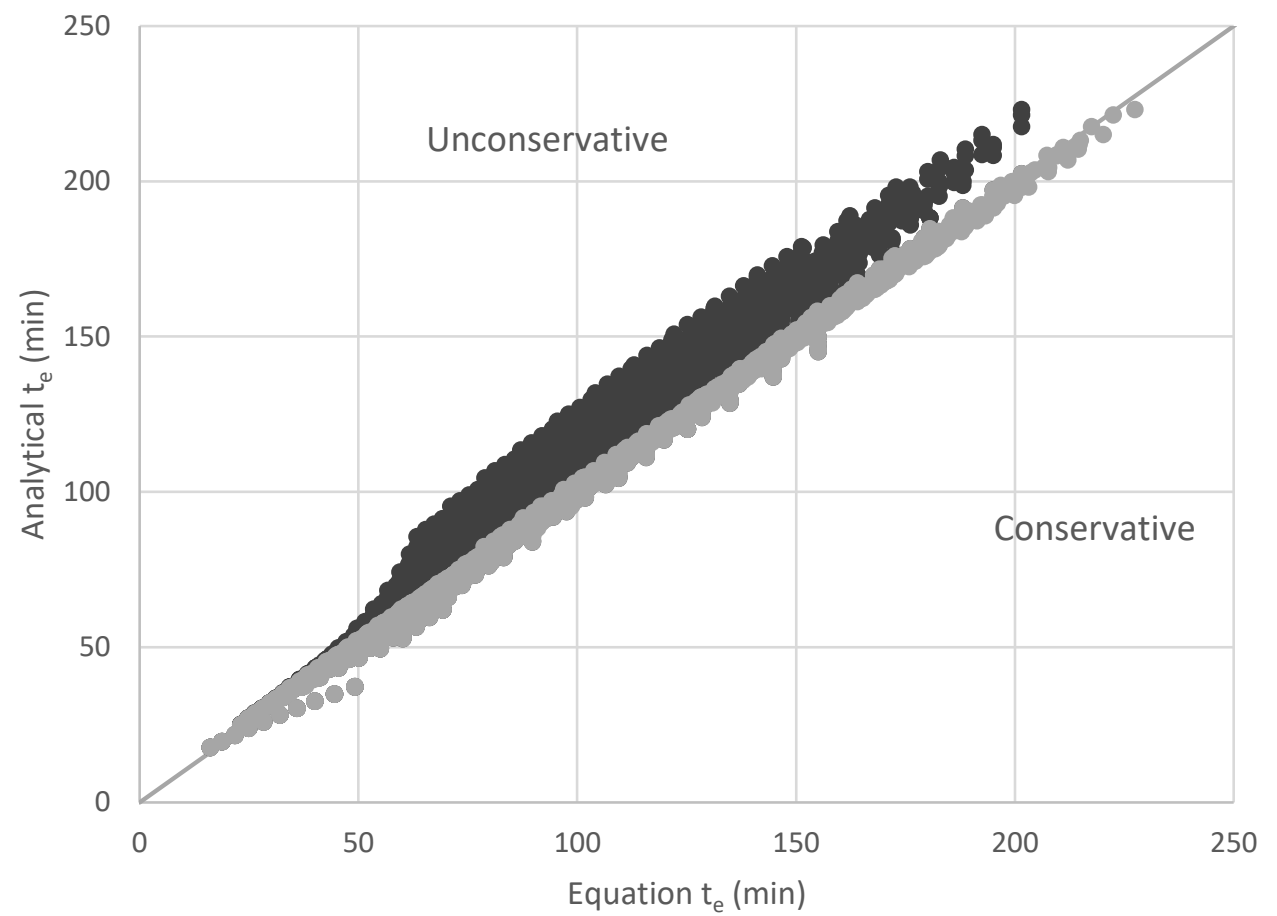

(a)

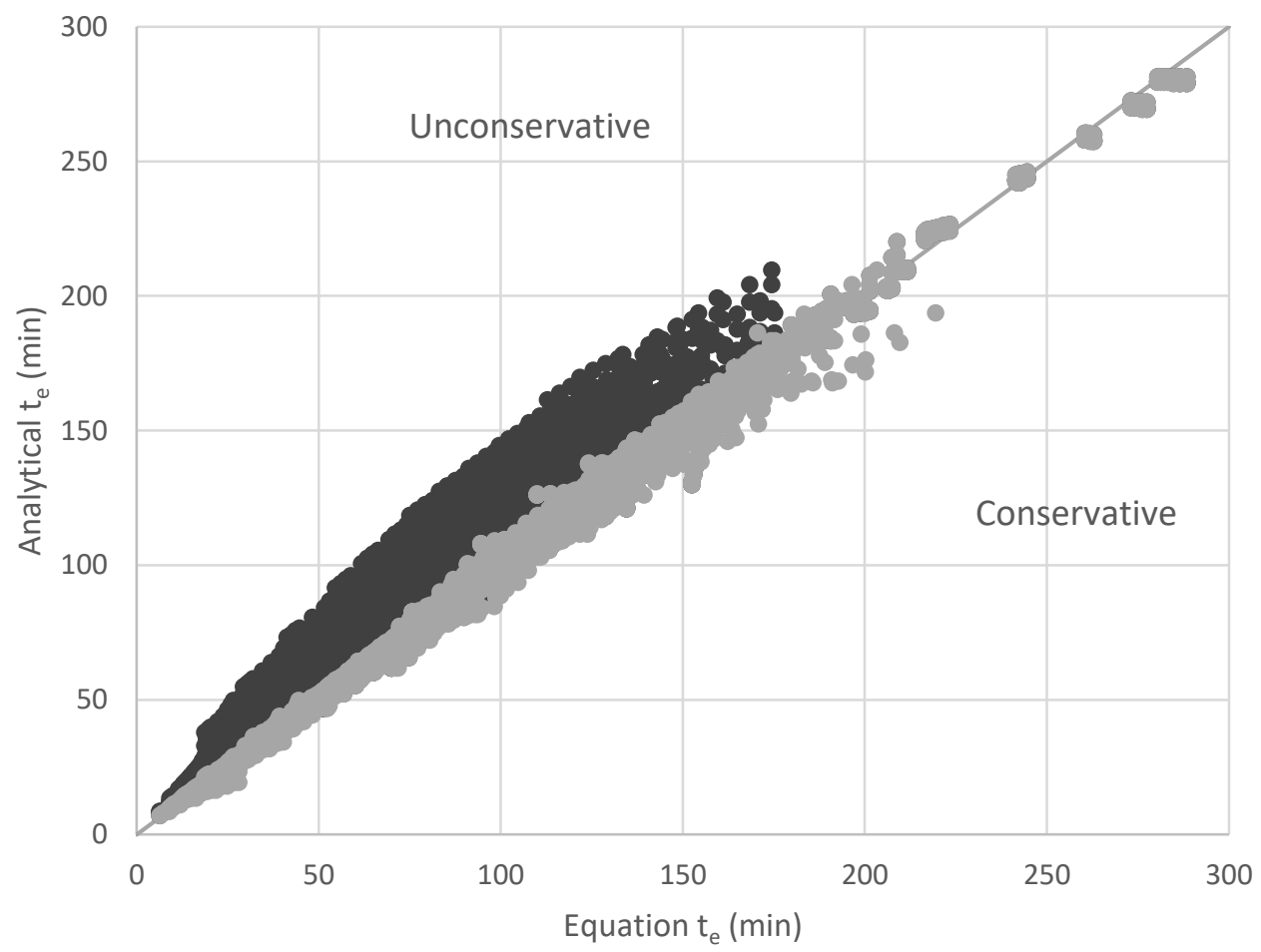

(b)

- Without Size adjustment Factor With Size adjustment Factor

Fig. 10. Analytical vs. Equation $t_{e}$ for: (a) Mean Criterion (b) Conservative Criterion with and without $\psi_{\text {size }}$ 


\section{Comparison with Existing Methods}

A comparison of existing methods is provided in Figures 11 to 16 for each of the six design fires. The referenced methods are sorted in pairs, featuring the early methods of Ingberg (1928) and Law (1971); the two code approaches of CIB (1986) and EN 1991-1-2 (2002); the RC Energy and MDM methods of Kodur et al. (2010); and the two AITP criteria. Each figure consists of three parts, displaying (a) the $t_{e,}$ (b) the normalized average error for a $250 \times 500 \mathrm{~mm}$ section, and (c) the normalized average error for an $800 \times 500 \mathrm{~mm}$ section. For the AITP criteria, the $t_{e}$ for the $800 \mathrm{x}$ $500 \mathrm{~mm}$ section with $\psi_{\text {size }}$ is indicated by the checkered bar. All $t_{e}$ durations are calculated based on the ISO standard fire. It should be noted that the small fires FR 1 and FR 4 possess a $T_{\max }<$ $600^{\circ} \mathrm{C}$, and therefore do not meet the conditions of the mean $\psi_{\text {size. }}$ FR 1 and FR 4 do however meet all of the requirements of the conservative criterion.

A major trend is apparent between the methods tailored for RC elements (AITP mean criterion; Energy by Kodur et al., 2010; and MDM by Kodur et al., 2010) and those based on steel members or compartment boundaries (all others). The non-RC methods result in significantly greater error than the RC methods for all six design fires, indicating their poor ability in representing the internal temperature gradients. The only exception is Kodur et al.'s (2010) MDM, as it displays larger discrepancy for FR 1 and FR 4, this limitation for smaller fires is highlighted in the original publication. In the case of the moderate and larger fires of FR 2 and FR 3 (Figures 12 and 13), the non-RC methods result in a $t_{e}$ almost half that of the AITP mean, producing significantly unconservative estimates. For the small fire FR 4 (Figure 14), the $t_{e}$ of the non-RC approaches are more than double the AITP mean duration, resulting in massively conservative estimates of the 
fire's severity. As noted earlier, the conditions of the AITP mean criterion exclude its application for fire FR 4. Regardless, the mean criterion and the conservative criterion still exhibit far greater correlation between AITP-D and AITP-S than the existing methods. These discrepancies between the $\mathrm{RC}$ and non-RC methods highlight the importance of considering internal temperature profiles when developing and utilizing a time equivalent method for RC elements.

In comparison with the existing RC-methods by Kodur et al. (2010), AITP mean always results in the lowest error when representing the internal temperature profile. Particularly in the case of the rapid hot fire FR 5 (Figure 15), AITP mean produces results which are $152 \%$ more accurate than Kodur et al.'s MDM. Additionally, Kodur et al.'s Energy and MDM methods alternate on which is more accurate depending on the design fire and the section size. This is most apparent when comparing differences between FR 1 and FR 2; and between $250 \mathrm{~mm}$ and $800 \mathrm{~mm}$ wide sections for FR 6. Using the AITP mean criterion, the most accurate representation of the internal profiles is reliably developed for every design fire and every section size. Some discrepancy in Kodur et al.'s (2010) results can be attributed to its development based on the ASTM standard fire, however this should play only a very minor role in the results.

The impact of the $\psi_{\text {size }}$ is most noticeable for the longer duration fires of FR 2, FR 3, and FR 6 . The long cool FR 6 demonstrates the most significant impact, as the conservative $t_{e}$ is increased by almost 50 min between the 250 and $800 \mathrm{~mm}$ width sections (Figure 16). For FR 6, application of the $\psi_{\text {size }}$ allows the mean AITP to remain more accurate than Kodur et al.'s methods and the conservative AITP to be more reasonably conservative than the non-RC methods. Similar trends 
are apparent for FR 2 and FR 3. The $\psi_{\text {size }}$ plays a crucial role in ensuring the accuracy and conservativeness of the AITP methods in comparison to the existing approaches. 


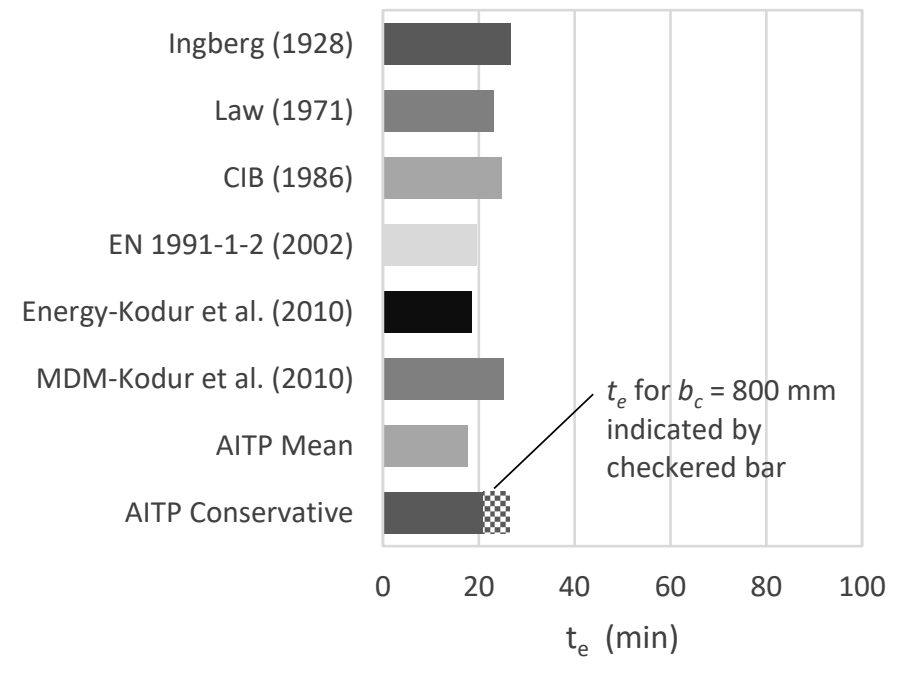

(a)

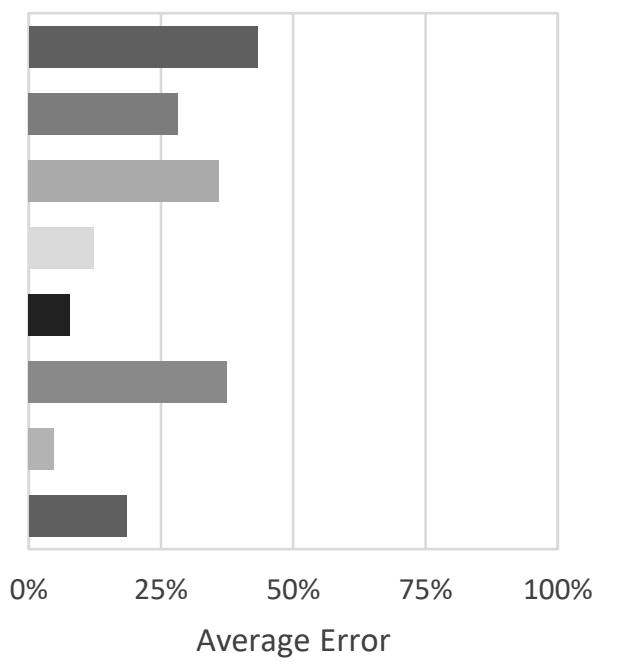

(b)

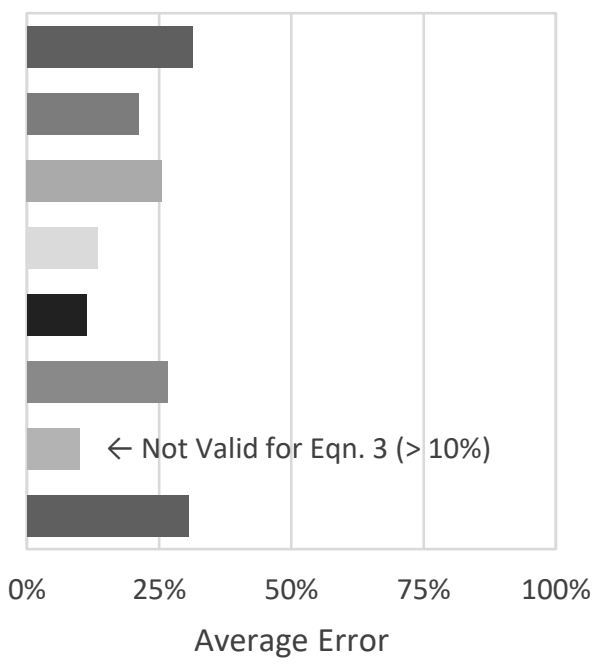

(c)

Fig 11. Comparison of Existing Methods on Moderate FR 1 for (a) $t_{e}$ (b) Average Error for $250 \mathrm{~mm}$ Width, and (c) Average Error for $800 \mathrm{~mm}$ Width

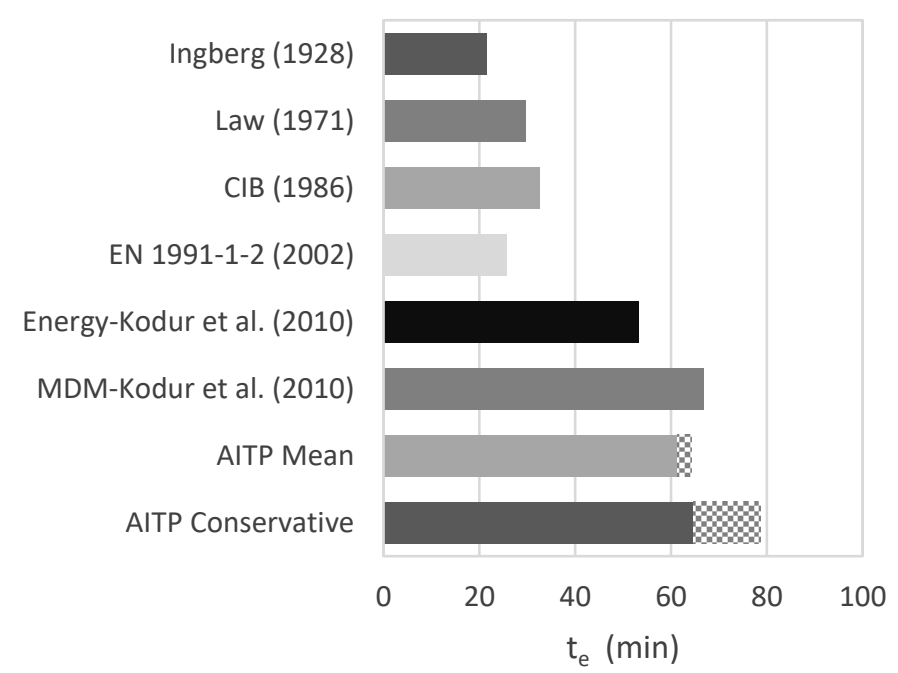

(a)

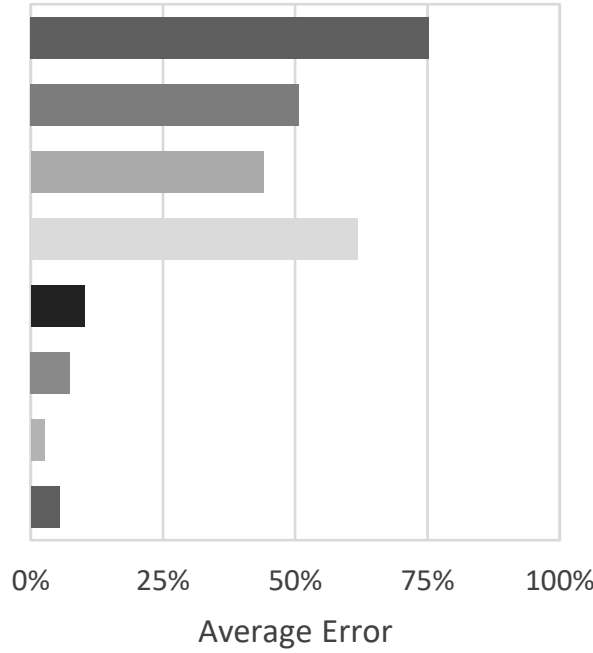

(b)

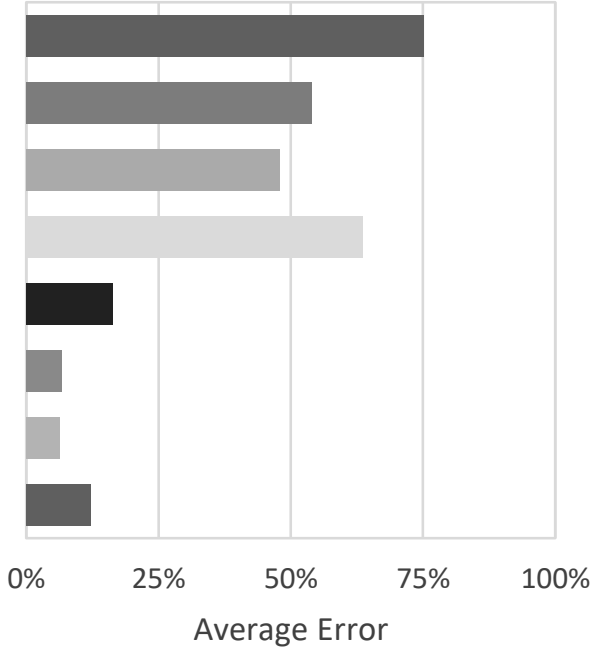

(c)

Fig 12. Comparison of Existing Methods on Moderate FR 2 for (a) $t_{e_{l}}$ (b) Average Error for 250 mm Width, and (c) Average Error for $800 \mathrm{~mm}$ Width 


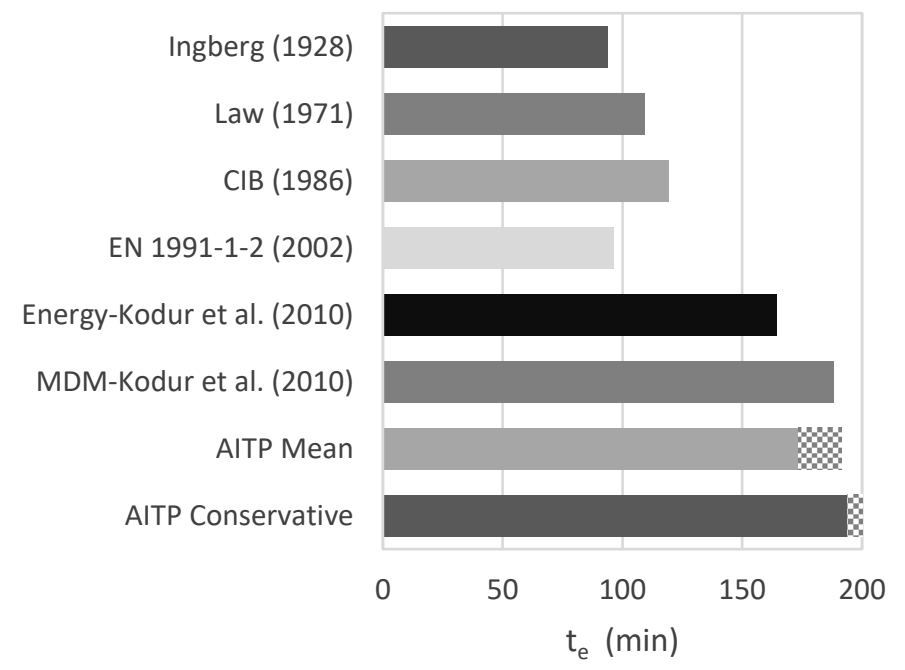

(a)

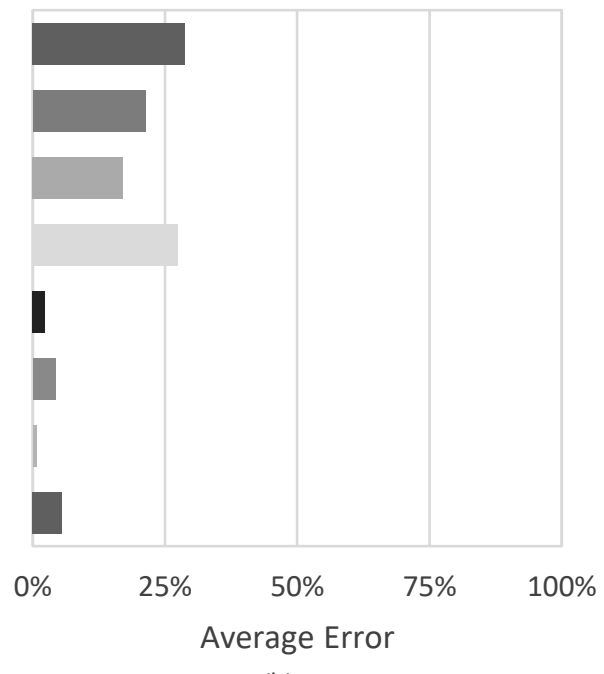

(b)

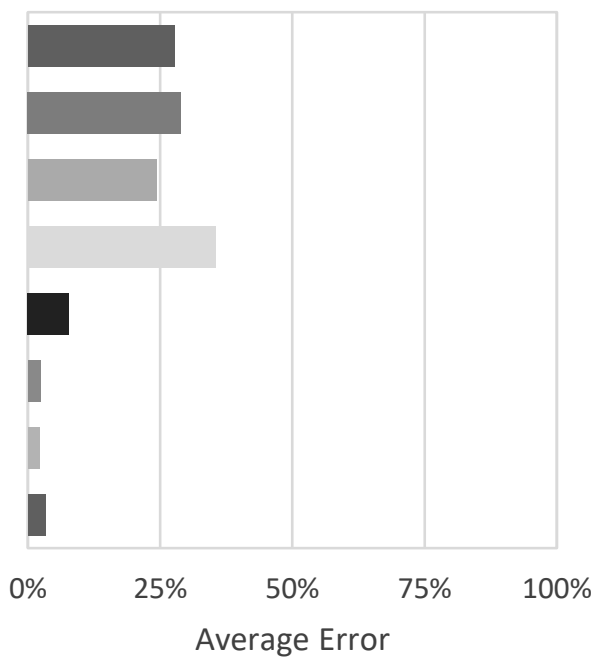

(c)

Fig 13. Comparison of Existing Methods on Large FR 3 for (a) $t_{e_{1}}$ (b) Average Error for $250 \mathrm{~mm}$ Width, and (c) Average Error for $800 \mathrm{~mm}$ Width

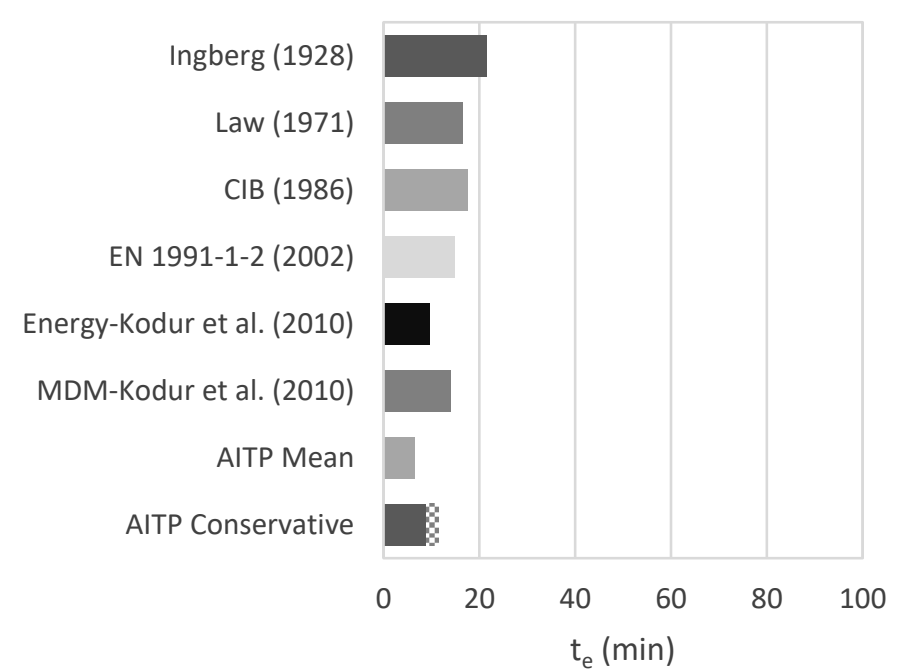

(a)

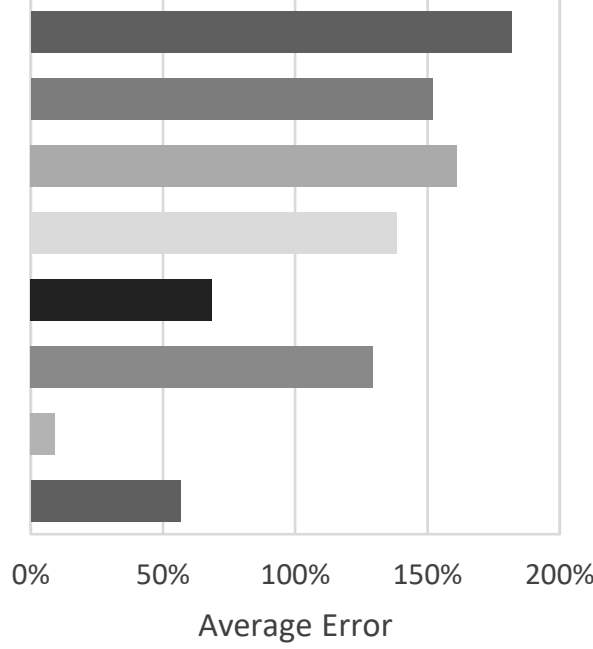

(b)

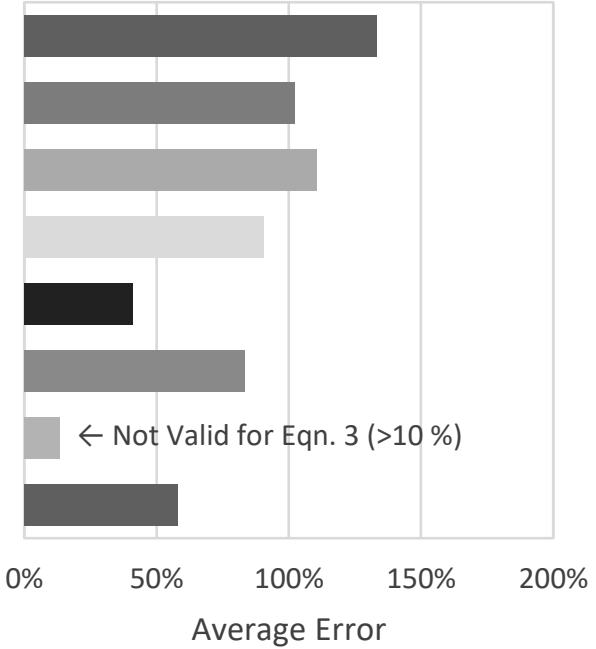

(c)

Fig 14. Comparison of Existing Methods on Small FR 4 for (a) $t_{e}$ (b) Average Error for $250 \mathrm{~mm}$ Width, and (c) Average Error for $800 \mathrm{~mm}$ Width 


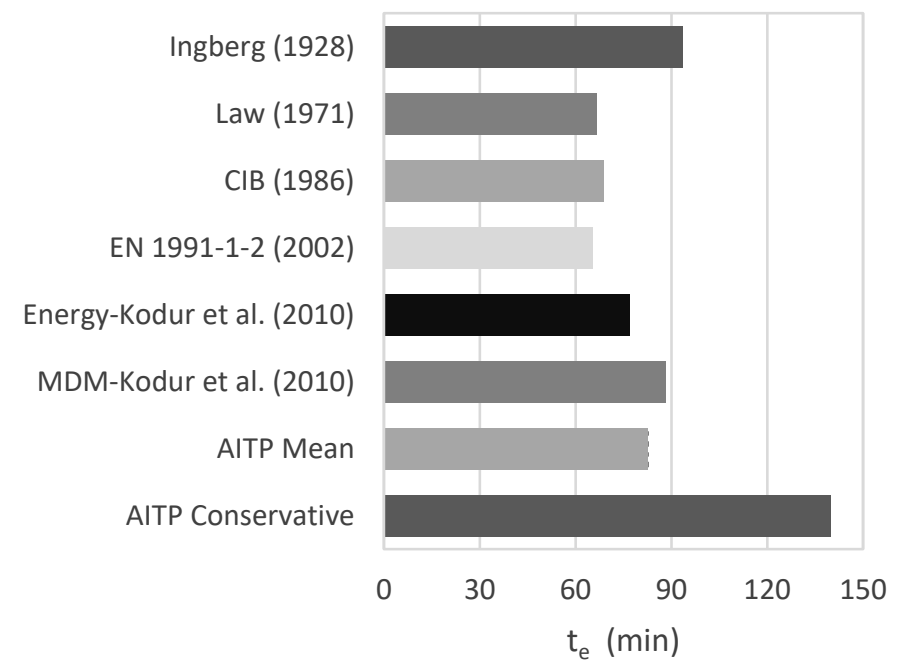

(a)

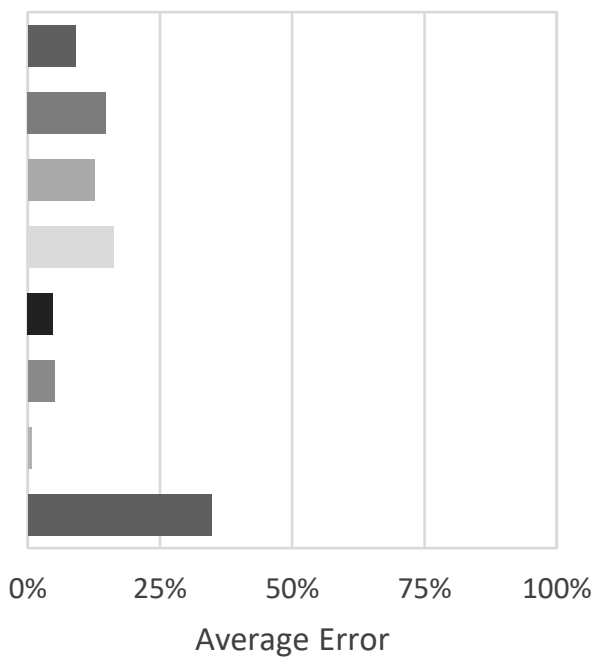

(b)

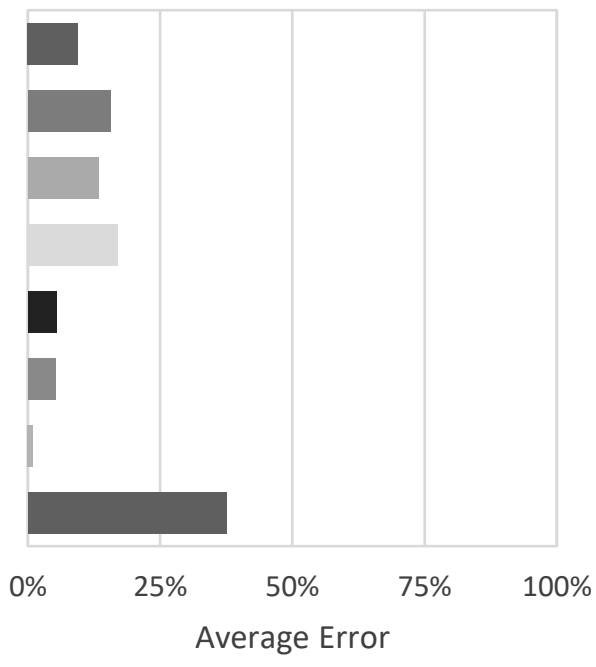

(c)

Fig 15. Comparison of Existing Methods on Rapid Hot FR 5 for (a) $t_{e}$ (b) Average Error for $250 \mathrm{~mm}$ Width, and (c) Average Error for $800 \mathrm{~mm}$ Width

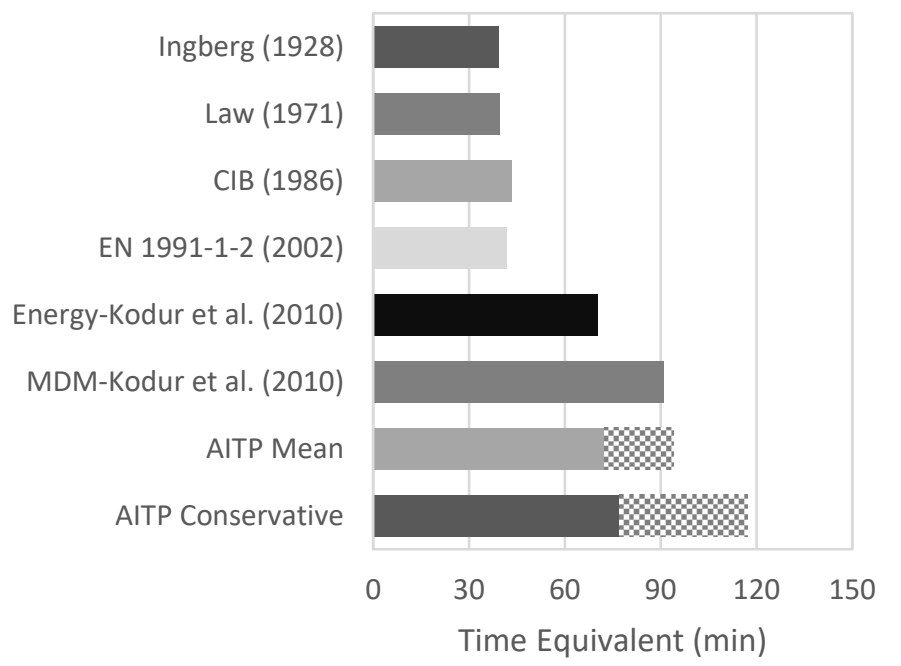

(a)

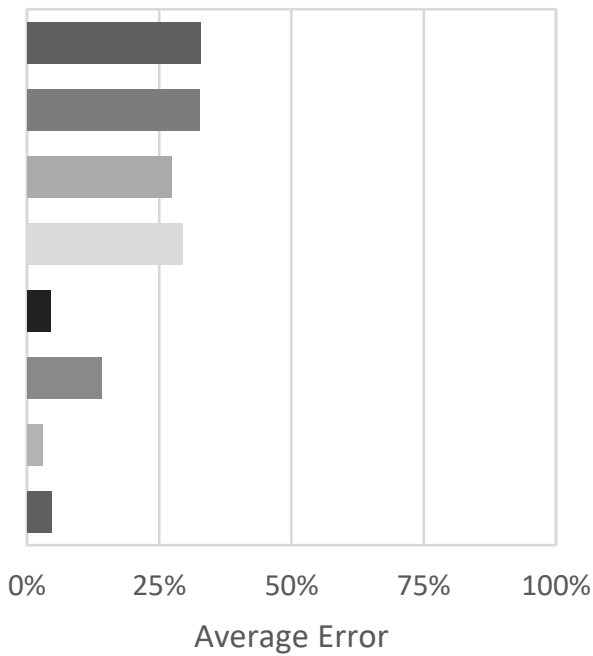

(b)

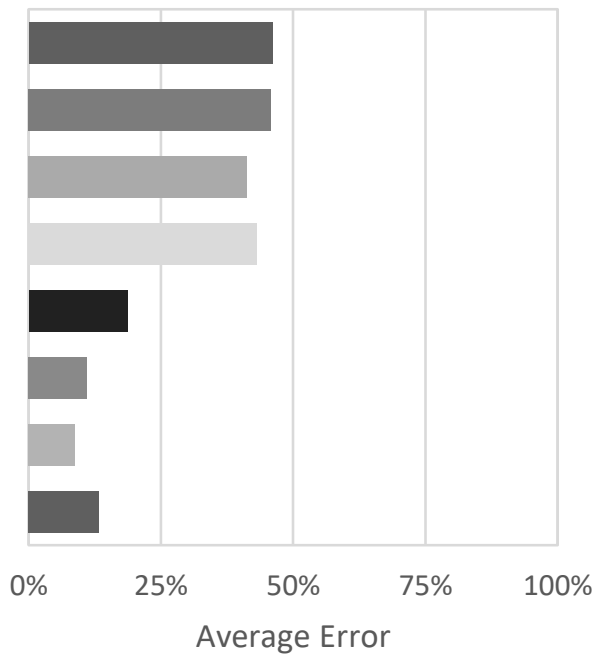

(c)

Fig 16. Comparison of Existing Methods on Long Cool FR 6 for (a) $t_{e}$ (b) Average Error for 250 mm Width, and (c) Average Error for 800 mm Width 


\section{Conclusion}

To better facilitate performance-based design, time equivalent methods are needed to assess the severity of a natural fire in terms of the duration of a standard fire. Using a time equivalent $\left(t_{e}\right)$, engineers can easily relate natural fires to the wealth of available data, testing, and computer programs based on standard fire curves. Existing time equivalent methods in the literature and design manuals have been proven to be largely inaccurate in representing the internal thermal gradient of RC elements exposed to fire. To better address time equivalency for RC elements, a new AITP method was introduced, which bases equivalency on the actual internal temperature profiles of RC beams.

To develop the AITP method, a parametric study was conducted on a $250 \times 500 \mathrm{~mm}$ RC section exposed to 1290 design fires. Two equations were developed for the AITP method: mean and conservative. Mean criterion was based on accurately matching the internal temperature profiles of a design fire to that of a standard, while conservative criterion was based on selecting the shortest duration standard fire that produces equal or larger temperatures at every point in a section. Further evaluation regarding the influence of section dimensions on the $t_{e}$ revealed the importance of accounting for section width. A size adjustment factor $\left(\psi_{\text {size }}\right)$, to be used in conjunction with the $t_{e}$, was proposed to address this observation. In comparison with existing methods, the AITP mean criterion displayed far greater accuracy in representing the internal temperature gradient, and the AITP conservative criterion the only method capable of consistently being conservative. The proposed $t_{e}$ is valid for beams exposed to natural fire on three sides, within the ranges of $150^{\circ} \mathrm{C} \leq$ maximum temperature $\left(T_{\max }\right) \leq 1200^{\circ} \mathrm{C}, 20$ min $\leq$ time of maximum 
temperature $\left(t_{\max }\right) \leq 115 \mathrm{~min}$, and $20 \mathrm{~min} \leq$ overall duration $\left(t_{\text {final }}\right) \leq 240 \mathrm{~min}$. Using the proposed AITP method, designers can quickly relate the severity of a natural fire to an equivalent standard fire, allowing them to utilize existing standard fire resources.

\section{References}

Alhadid, M. Behavior of Fire-Exposed RC Frames Before and After Jacketing. Diss. Department of Civil and Environmental Engineering, Western University, 2017.

ASTM E-119. Standard Test Methods for Fire Tests of Building Construction and Materials. American Society for Testing and Materials. West Conshohocken, PA, USA. 2018.

Buchanan, A. H. Structural Design for Fire Safety. $2^{\text {nd }}$ ed. Wiley, 2001.

CIB. "Design Guide: Structural Fire Safety CIB W14 Workshop Report." Fire Safety Journal, vol. 10, no. 2, 1986, pp. 77-137.

Cooper, L. Y., and K. D Steckler. Methodology for Developing and Implementing Alternative Temperature-Time Curves for Testing the Fire Resistance of Barriers for Nuclear Power Plant Applications. no. 5842, National Institute of Standards and Technology, Gaithersburg, MD, USA. 1996.

Dembsey, N. A., P. J. Pagni, and R. B. Williamson. "Compartment Fire Experiments: Comparison with Models." Fire Safety Journal, vol. 25, no. 1, 1995, pp. 187-227.

El-Fitiany, S. F., and M.A. Youssef. "Assessing the Flexural and Axial Behaviour of Reinforced Concrete Members at Elevated Temperatures Using Sectional Analysis." Fire Safety Journal, vol. 44, no. 5, 2009, pp. 691-703.

El-Fitiany, S. F., and M.A. Youssef. "Fire Performance of Reinforced Concrete Frames Using Sectional Analysis." Engineering Structures, vol. 142, no. 1, 2017, pp. 165-181. 
EN 1991-1-2. Eurocode 1: Actions on Structures - Part 1-2: Actions on structures Exposed to Fire. European Committee for Standardization. Brussels, Belgium. 2002.

Fackler, J. P. "Concernant la Resistance au feu des Elements de Construction." (In French). Cahiers du Centre Scientifique et Technique du Bâtiment, vol. 37, 1959, pp. 1-20.

Franssen, J. M., and T. Gernay. "Modeling Structures in Fire with SAFIR: Theoretical Background and Capabilities." Journal of Structural Fire Engineering, vol. 8, no. 3, 2017, pp. 300-323.

Gao, W. Y., J. G. Dai, and J. G Teng. "Simple Method for Predicting Temperatures in Reinforced Concrete Beams Exposed to a Standard Fire." Advances in Structural Engineering, vol. 17, no. 4, 2014, pp. 573-589.

Guo, Z., and X. Shi. Experiment and Calculation of Reinforce Concrete at Elevated Temperatures. Elsevier Ltd, 2011.

Harada, K., R. Kogure, K. Matsuyama, and T. Wakamtsu. "Equivalent Fire Duration Based on TimeHeat Flux Area." $4^{\text {th }}$ Asia-Oceania Symposium on Fire Science and Technology, Ottawa, Canada, 1994. Edited by T. Kashiwagi, Fire Safety Science, 2000, pp. 513-524.

Harmathy, T. Z., and J. R. Mehaffey. "The Normalized Heat Load Concept and Its Use." Fire Safety Journal, vol. 12, no. 1, 1987, pp. 75-81.

Implementation of Eurocodes. Handbook 5 - Design of Buildings for the Fire Situation. Leonardo Da Vinci Joint Research Project, 2005.

Ingberg, S. "Tests on the Severity of Building Fires." Quarterly of the National Fire Protection Association, vol. 22, 1928, pp. 43-61.

ISO 834. Fire Resistance Tests - Elements of Building Construction. International Organization for Standards. Geneva, Switzerland. 1999.

Kodur, V. K. R., P. Pakala, and M. B. Dwaikat. "Energy Based Time Equivalent Approach for Evaluating Fire resistance of Reinforced Concrete Beams." Fire Safety Journal, vol. 45, no. 4, 2010, pp. 211-220. 
Law, M. A Relationship Between Fire Grading and Building Design and Contents. no. 877, Building Research Establishment - Fire Research Note, UK, 1971.

Law, M. "A Review of Formulae For T-Equivalent." $5^{\text {th }}$ Asia-Oceania Symposium on Fire Science and Technology, Melbourne, Australia, 1997. Edited by H. Yuji, Fire Safety Science, 1997, pp 985-996.

Lennon, T. Results and Observations from Full-Scale Fire Test at BRE Cardington. no. 215-741, Building Research Establishment, Cardington, UK, 2004.

Lie, T. T. Structural Fire Protection. ASCE, 1992.

Nyman, J. F. Equivalent Fire Resistance Ratings of Construction Elements Exposed to Realistic Fires. MS. Department of Civil Engineering, University of Canterbury, 2002.

Pettersson, O. The Connection Between a Real Fire Exposure and the Heating Conditions According to Standard Fire-Resistance Tests - With Special Application to Steel Structures. bulletin no. 39, Lund Institute of Technology - Division of Structural Mechanics and Concrete Construction, Lund, Sweden, 1975.

Purkiss, J. A. Fire Safety Engineering, Design of Structures. Elsevier Ltd, 2007.

Schneider, U., M. Kersken-Bradley, and U. Max. Neuberechnung der Wärmeabzugsfaktoren w für die DINV 18230: Teil 1 - Baulicher Brandschutz Industribau. (In German). Fraunhofer IRB Verlag, Stuttgart, Germany, 1990.

Thomas, G. C., A. H. Buchanan, and C. M. Fleischmann. "Structural Fire Design: The Role of Time Equivalence." $5^{\text {th }}$ Asia-Oceania Symposium on Fire Science and Technology, Melbourne, Australia, 1997. Edited by H. Yuji, Fire Safety Science, 1997, pp 607-618.

Wade, C. A., J. T. Gerlich, and A. Abu. The Relationship Between Fire severity and Time-Equivalent. BRANZ Study Report 314, BRANZ, Porirua, New Zealand, 2014.

Wang, Y., I. Burgess, F. Wald, and M. Gillie. Performance-Based Fire Engineering of structures. Spon Press, 2013. 
Wickström, U. L. F. A Very Simple Method for Estimating Temperature in fire Exposed Concrete Structures. Technical Report SP-RAPP 1986:46, Swedish National Testing Institute, Boras, Sweden, 1986.

Xie, P., A. Abu, and M. Spearpoint. "Comparison of Existing Time-Equivalent Methods and the Minimum Load Capacity Method." $10^{\text {th }}$ Asia-Oceania Symposium on Fire Science and Technology, Tsukuba, Japan, 2015. Edited by K. Harada et al., Fire Science and Technology, 2015, pp 263-271.

Youssef, M. A., M. A. Diab, and S. F. El-Fitiany. "Shear Capacity of RC Beams at Elevated Temperatures." Magazine of Concrete Research, vol. 67, no. 22, 2015, pp. 1190-1203. 